Portland State University

PDXScholar

Master of Environmental Management Project

Reports

Environmental Science and Management

Winter 2020

\title{
Collecting Plant Phenology Data in Imperiled Oregon White Oak Ecosystems: Analysis and Recommendations for Metro
}

Kirsten Wright

Portland State University

Follow this and additional works at: https://pdxscholar.library.pdx.edu/mem_gradprojects

Part of the Environmental Health and Protection Commons, Environmental Monitoring Commons, and the Natural Resources and Conservation Commons

Let us know how access to this document benefits you.

\section{Recommended Citation}

Wright, Kirsten, "Collecting Plant Phenology Data in Imperiled Oregon White Oak Ecosystems: Analysis and Recommendations for Metro" (2020). Master of Environmental Management Project Reports. 61. https://pdxscholar.library.pdx.edu/mem_gradprojects/61

https://doi.org/10.15760/mem.64

This Project is brought to you for free and open access. It has been accepted for inclusion in Master of Environmental Management Project Reports by an authorized administrator of PDXScholar. Please contact us if we can make this document more accessible: pdxscholar@pdx.edu. 
Collecting Plant Phenology Data

In Imperiled Oregon White Oak Ecosystems:

Analysis and Recommendations for Metro

Master of Environmental Management

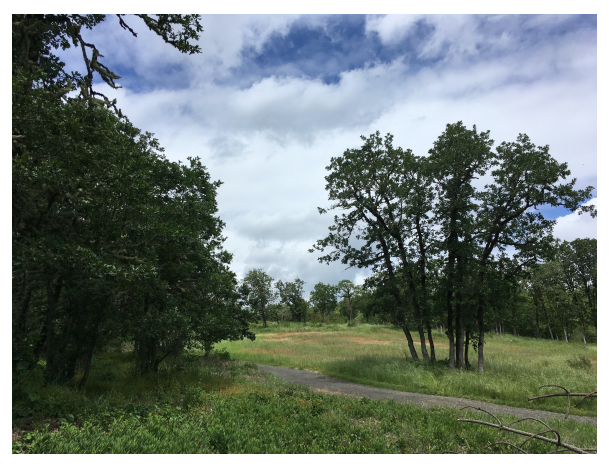

Submitted to

Oregon Metro

and

The Department of Environmental Science and Management

Portland State University

Submitted by

Kirsten Wright

March 2020 


\section{Acknowledgements}

I would like to acknowledge the many individuals who supported this project, with special thanks to my advisor Dr. Jeff Gerwing and committee members Dr. Sarah Eppley and Marsha HoltKingsley. Thank you for sharing your expertise, investing your time and providing invaluable insight.

I've been incredibly fortunate to work with Metro's plant materials scientists over the last few years: such an amazing, innovative, hard-working group. Thank you for trusting me to work on this project and for providing so much insight as the project changed and developed.

I would also like to thank the PSU herbarium staff and the many scientists who contributed their expertise to shape this project. I appreciate your overwhelming support and guidance.

And finally, my family, with particular thanks to my husband, Thom Kasten. I am forever grateful for your steadfast support throughout this entire process. 
Table of Contents

I. Project

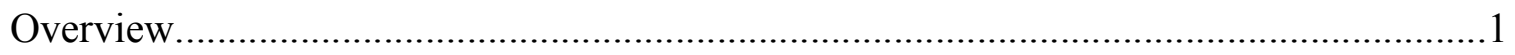

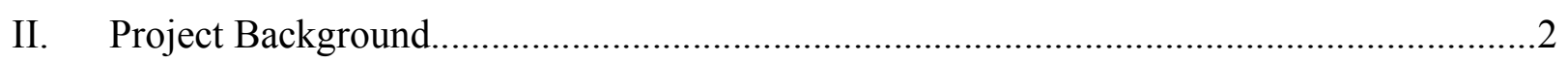

Description of Oregon White Oak Systems ....................................................................2

Threats to Oregon White Oak Systems.............................................................................. 3

Phenology as an Indicator of Environmental Change ..................................................4

Herbarium Specimens as a Teaching Tool.................................................................. 4

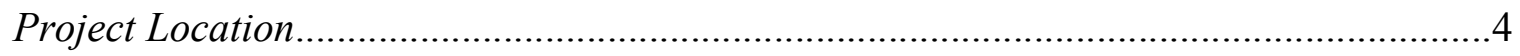

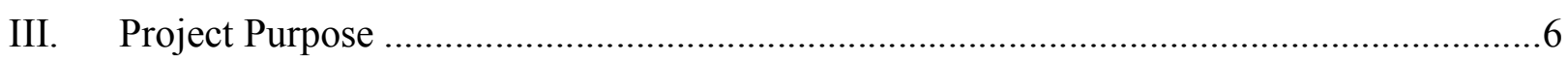

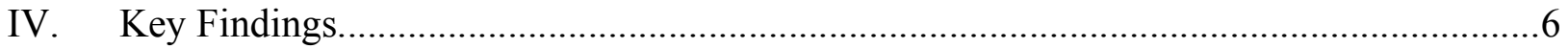

Part 1: Evaluating Metro's Plant Phenology Data and Methods (2012-2017).................6

Part 2: Recommendations for Data Collection and Sharing .........................................15

Species Selection ........................................................................................ 16

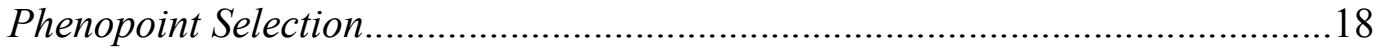

Data-Sharing With Other Organizations..........................................................20

Part 3: Creating Educational Vouchers for Metro's Teaching Herbarium......................22

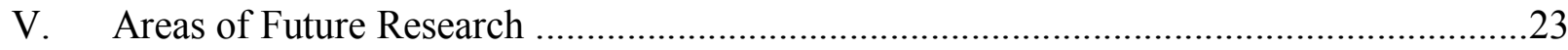

VI. Cited Literature and Communication..................................................................25

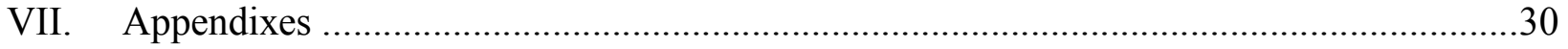

Appendix A -Tables of Plants and Environmental Attributes........................................30

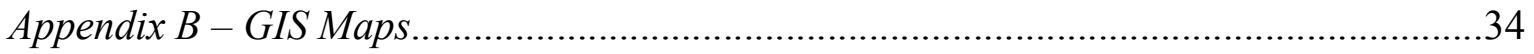

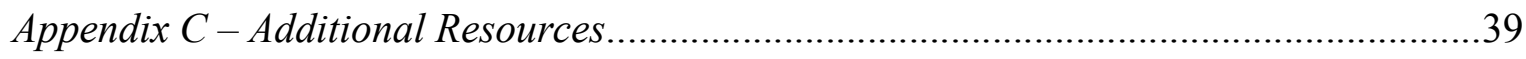




\section{List of Tables}

Table 1 . Species identified as a conservation priority by Metro, not represented in phenology data collected from 2012 to 2017

Table 2. Species aligned with data collected in the Willamette Valley by horticulturist Wilbur Bluhm.

Table 3. Species associated with at-risk clades identified by Willis et al. (2008) .........................31

Table 4. Environmental attributes of 40 existing phenopoints

\section{List of Figures}

Cover image: Cooper Mountain oak system restoration area

Figure 1. Decline of oak habitat in the Willamette Valley from 1938-2013 (Willamette Partnership 2016) 3

Figure 2. Map of regional Metro properties...........................................................................

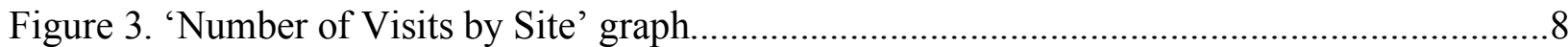

Figure 4. 'Mean Observed Species per Year' graph...................................................................

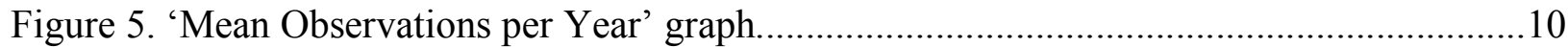

Figure 6. 'Total Observations' graph..................................................................................11

Figure 7. 'Forbs and Graminoids Total Observations' graph.....................................................12

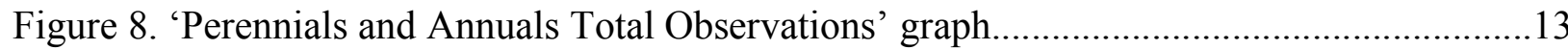

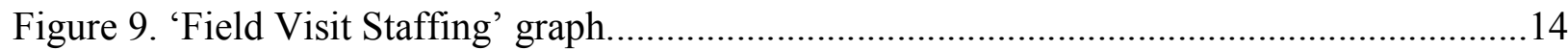

Figure 10. Map of four Metro sites currently containing phenopoints.........................................19

Figure 11. USA-National Phenology Network data flow diagram (Rosemartin 2013).................21

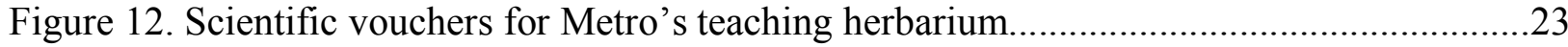

Figure 13. Environmental attribute map of Canemah Bluff: aspect...............................................34

Figure 14. Environmental attribute map of Canemah Bluff: slope..................................................

Figure 15. Environmental attribute map of Cooper Mountain: aspect............................................35

Figure 16. Environmental attribute map of Cooper Mountain: slope.............................................35

Figure 17. Environmental attribute map of Willamette Narrows Forest Complex: aspect............36

Figure 18. Environmental attribute map of Willamette Narrows Forest Complex: slope..............36

Figure 19. Environmental attribute map of project area: elevation.................................................

Figure 20. Environmental attribute map of project area: soil types..............................................38 


\section{Project Overview}

Highly imperiled Oregon white oak ecosystems are a regional conservation priority of numerous organizations, including Oregon Metro, a regional government serving over one million people in the Portland area. Previously dominant systems in the Pacific Northwest, upland prairie and oak woodlands are now experiencing significant threat, with only $2 \%$ remaining in the Willamette Valley in small fragments (Hulse et al. 2002). These fragments are of high conservation value because of the rich biodiversity they support, including rare and endemic species, such as Delphinium leucophaeum (Oregon Department of Agriculture, 2020).

Since 2010, Metro scientists and volunteers have collected phenology data on approximately 140 species of forbs and graminoids in regional oak prairie and woodlands. Phenology is the study of life-stage events in plants and animals, such as budbreak and senescence in flowering plants, and widely acknowledged as a sensitive indicator of environmental change (Parmesan 2007). Indeed, shifts in plant phenology have been observed over the last few decades as a result of climate change (Parmesan 2006). In oak systems, these changes have profound implications for plant community composition and diversity, as well as trophic interactions and general ecosystem function (Willis 2008).

While the original intent of Metro's phenology data-collection was to track long-term phenology trends, limitations in data collection methods have made such analysis difficult. Rather, these data are currently used to inform seasonal management decisions on Metro properties, such as when to collect seed for propagation and when to spray herbicide to control invasive species. Metro is now interested in fine-tuning their data-collection methods to better capture long-term phenology trends to guide future conservation strategies.

Addressing the regional and global conservation issues of our time will require unprecedented collaboration. Phenology data collected on Metro properties is not only an important asset for Metro's conservation plan, but holds potential to support broader research on a larger scale. As a leader in urban conservation, Metro is poised to make a meaningful scientific contribution by sharing phenology data with regional and national organizations. Data-sharing will benefit the common goal of conservation and create avenues for collaboration with other scientists and conservation practitioners (Rosemartin 2013).

In order to support Metro's ongoing conservation efforts in Oregon white oak systems, I have implemented a three-part master's project. Part one of the project examines Metro's previously collected phenology data, providing descriptive statistics and assessing the strengths and weaknesses of the methods by which the data were collected. Part two makes recommendations for improving future phenology data-collection methods, and includes recommendations for datasharing with regional and national organizations. Part three is a collection of scientific vouchers 
documenting key plant species in varying phases of phenology for Metro's teaching herbarium. The purpose of these vouchers is to provide a visual tool for Metro staff and volunteers who rely on plant identification to carry out aspects of their job in plant conservation. Each component of this project addresses specific aspects of Metro's conservation program, from day-to-day management concerns to long-term scientific inquiry.

\section{Project Background}

\section{Description of Oregon White Oak Systems}

Oregon white oak ecosystems include upland prairie and woodlands populated with Oregon white oak (Quercus garryana) and an assemblage of herbaceous species that thrive under the same relative conditions. Oregon white oak ecosystems range from central California to British Columbia, and includes the length of the Willamette Valley through central and northern Oregon (Thilenius 1968). Upland prairies are characterized by open meadows of grasses and forbs, and a widely-spaced distribution of oak trees. Oak woodlands are comprised of smaller trees, with a density of 30 to 70 percent canopy cover (Oregon Conservation Strategy, 2020). Historically, the Willamette Valley was dominated by Oregon white oak habitat, arranged in loose bands of grassland and woodlands (Christy and Alverson 2011).

Oak habitat is adapted to thrive under a disturbance regime of low-intensity fire, which prevents the establishment of fast-growing tree species, helps return nutrients to the soil and reduces the threat of pests and disease (Cavender-Bares and Reich 2012). For millennia indigenous people of the Pacific Northwest maintained oak habitat with low intensity fires, which kept the landscape open and improved conditions for hunting and gathering (Thilenius 1968; Walsh 2010). As an important food source, Quercus garryana represents a cultural keystone species for indigenous people (Garibaldi and Turner 2004) in the Willamette Valley ecoregion and beyond. Current remaining fragments of oak habitat serve as an important cultural legacy, supporting the heritage of First Nations people.

An important asset of Oregon white oak ecosystems is the abundant biodiversity they support. Considered among the biologically richest ecosystems in the Pacific Northwest, Oregon white oak prairie and woodlands support over 200 native species of wildlife (Vesely and Tucker 2004) and 350 native species of plants (Apostol and Sinclair 2006). This includes rare and endemic plant species, such as Delphinium leucophaeum (Oregon Department of Agriculture 2020), as well as threatened and endangered wildlife, such as Fender's blue butterfly (Icaricia icarioides fenderi) (U.S. Fish and Wildlife 2020).

Remaining fragments of oak prairie and woodlands serve as refugia for numerous species, with particular significance in urban areas. Under growing pressure of urbanization, endemic species 
are often extirpated, causing homogenization of global biodiversity. Fragments of Oregon oak ecosystems create a refuge for flora and fauna faced with powerful competitive pressure by nonnative species associated with urbanization. These ecosystem fragments provide source populations for native species inhabiting urban "sinks," which possess insufficient resources to maintain a viable population on their own (Adler and Tanner, 2013). Preserving and enhancing a network of habitat patches in these fragments will support metapopulations (Hanski and Ovaskainen 2002) and offset some of the negative effects of urbanization on the region's biodiversity.

\section{Threats to Oregon White Oak Systems}

Following European settlement in the mid-1800's, conversion to agriculture, urban development, fire suppression and invasive species have resulted in substantial habitat loss and degradation of Oregon white oak ecosystems (Dennehy 2011, Dunwiddie \& Bakker 2011). Currently, less than $2 \%$ of historic white oak habitat remains in the Willamette Valley (Hulse et al. 2002, Figure 1. Willamette Partnership 2016).
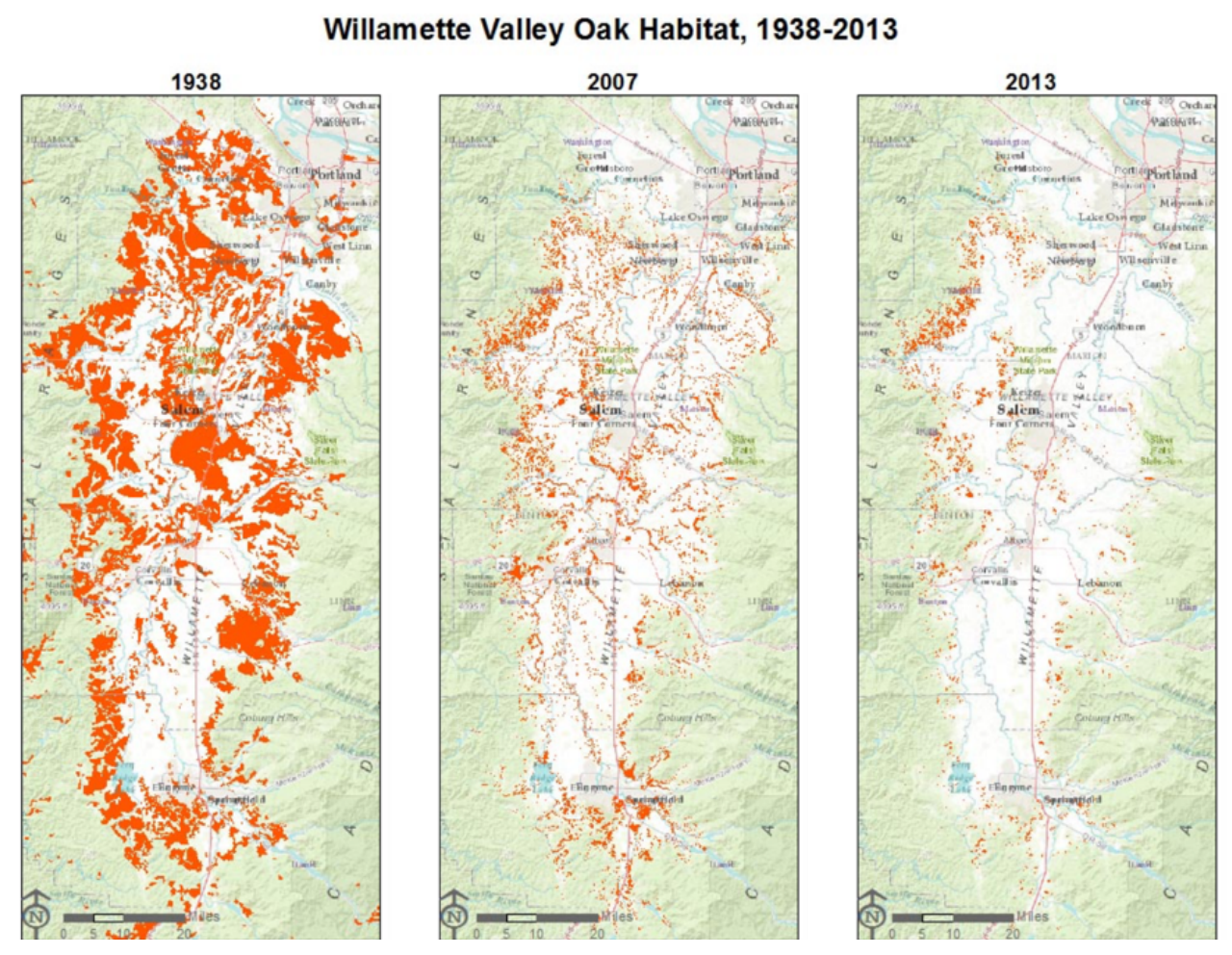

Figure 1. Illustrates the decline of oak habitat (orange area) in the Willamette Valley between 1938 and 2013. (Image courtesy of Willamette Partnership, 2016).

In recent years, climate change has emerged as an additional threat, with potential to alter sensitive systems even further (Penuelas \& Filella 2001). In the Pacific Northwest, climate models predict 
an increase in annual temperature and a change in precipitation regimes (Bachelet et al. 2011). As a result, oak systems and other grasslands are predicted to suffer a loss in overall diversity and frequency of native species, experience a shift in suitable range and suffer under extreme pressure from invasive species (Pfeifer-Meister et al., 2013, Bachelet et al. 2011). These changes may lead to novel community assemblages of species and modified ecosystem function (Pfeifer-Meister 2016).

\section{Phenology as an Indicator of Environmental Change}

Phenology is considered a highly sensitive indicator of environmental change (Parmesan 2007). Thus, observing and documenting phenology is an important research strategy to quantify change within sensitive plant communities. Considering the potential for asynchronicities between plants and pollinators and a cascade effect through trophic levels as a result of phenological changes, such research is critical (Stucky 2018; Whittington et al. 2015). These data can help make predictions about how plant communities will respond to future effects of climate change, identify vulnerable species and guide management strategies (Crimmins 2017, Davies 2013). In the Pacific Northwest, the advancement of phenology research is vital: recent analysis of long-term phenology data from the Willamette Valley confirms that phenology of regional plants is already advancing (Lindh and Bluhm 2018).

\section{Herbarium Specimens as a Teaching Tool}

Herbarium specimens are a valuable resource with numerous education applications (Culley 2013). One such application is the use of mounted specimens as a tool for plant identification. A well-mounted specimen captures remarkable details of plant anatomy, including reproductive structures and the nuances of leaf morphology. Viewers have the luxury of studying these specimens indoors in a well-lit space rather than out in the field, where windy or wet conditions can make fine-grain botanical observations difficult. In addition, two herbarium vouchers of closely resembling species can be placed side-by-side for comparison.

\section{Project Location}

Data collection from 2012-2019 occurred on 12 Metro properties throughout the Portland Metro area, stretching West of Beaverton to East of Oregon City (Figure 2). Specimen collection for scientific vouchers occurred on five Metro properties and one additional location in the Portland area. The five Metro properties were: Canemah Bluff, Clackamas Cliffs, Cooper Mountain, Metro's Native Plant Center and Tonquin Scablands. 


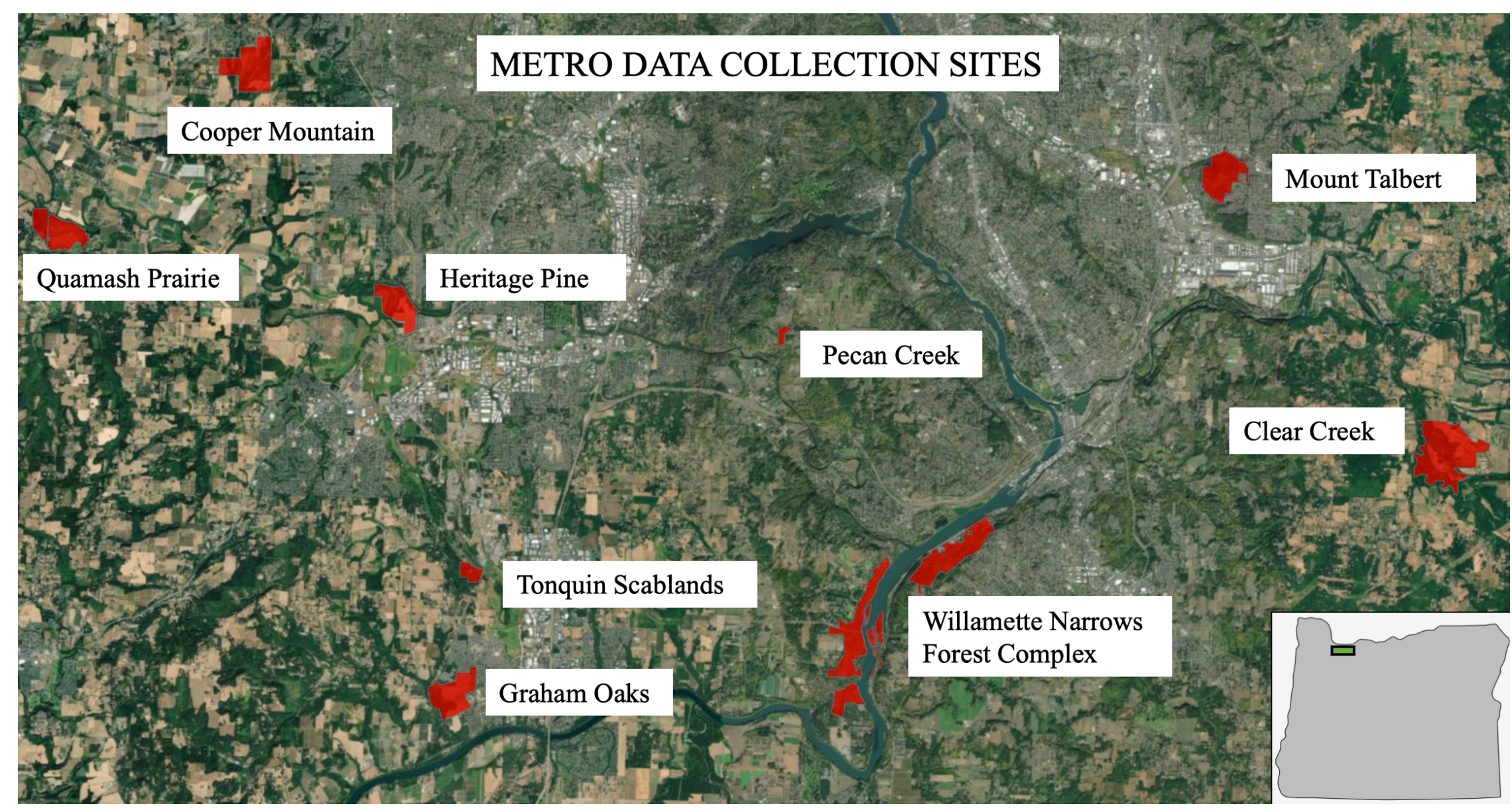

Figure 2. Regional Metro properties where data collection occurred from 2012-2019. 


\section{Project Purpose}

The purpose of this project is to support the goals of Metro's plant conservation program and increase the impact of Metro's monitoring efforts through data-sharing with other organizations. Each component of this project addresses specific aspects of Metro's conservation program: assessing the strengths and weaknesses of Metro's previously collected phenology data, providing recommendations for future methodology and data-sharing, and creating scientific vouchers for Metro's teaching herbarium. Collectively, this project supports the long-term objective of phenological monitoring: to understand how plant populations will respond to a shift in climate, in order to predict changes to community structure. Such data may identify conservation priorities and inform management strategies to strengthen and diversify fragile plant communities and the trophic interactions they support.

The overarching goal of this project is to preserve the health of Oregon white oak systems. This goal is aligned with priorities of the Willamette Valley Conservation Study (U.S. Fish and Wildlife Service 2017), the Oregon Conservation Strategy for the Willamette Valley ecoregion (Oregon Department of Fish and Wildlife 2016) and the Regional Conservation Strategy for the greater Portland-Vancouver region (the Intertwine Alliance 2012).

\section{Key Findings}

\section{Part 1: Evaluating Metro's Existing Plant Phenology Data and Methods}

a. Existing Plant Phenology Data (2012-2017) and Visits Data (2012-2019)

Phenology and 'Visits' data collected by staff and volunteers from 2012 to 2017 were consolidated by Al Mowbray, a research specialist with Metro. Phenology data describes the phenophases of observed species, and 'Visits' data record details of each field visit, such as which staff members or volunteers were present. The data were originally documented on paper data-collection sheets during field visits and transferred to a similar electronic Google form upon return from the field. To clean the data, incomplete entries - such as those missing the date, or observations in which plants were identified by genus but not species - were removed and the remaining data were consolidated into Excel spreadsheets.

To reduce the possibility of misidentified species, I removed additional entries from the phenology data in which a species was only recorded at a given site once during the period of 2012-2017. I also eliminated entries with insufficient data that were not removed during the initial cleaning. Following these parameters, I removed 272 entries out of 5269. In addition to the data organized by Al Mowbray, I manually consolidated 'Visits' data from 2018 and 2019 electronic data sheets for the purpose of analysis. While the 2018 and 2019 phenology data were not included in this 
analysis, the evaluation structure created here may provide a useful format for future analysis when the most current data are available. It is important to note that future analysis of the 2018 and 2019 data will likely change the outcome of key findings, and those presented in this report are based on the data currently available.

Using the data set, I sought to answer research questions originally formulated during discussions with Metro scientists. These questions were designed to give an overview of data previously collected, illuminate strengths and weakness in the data and collection methods, and identify gaps to be addressed in future data-collection efforts. This analysis may also help maximize future volunteer efforts. To answer the following research questions, I examined the data in numerous ways: at the site level, species level, as well as by functional groups and life-history strategies. I also quantified staffing of field visits to look for staffing trends during the research period.

What Metro sites are best represented by the phenology data from 2012-2017 and 'Visits' data 2012-2019?

Are there Metro sites not adequately represented in the data?

These questions were answered by looking at both frequency of visits per site and number of species observed per site during the study period. To begin, I examined 'Visits' data from 2012 to 2019 to identify which sites received the most field visits during the research period. Each visit represents a 'phenological snapshot' of select plant populations at that site on that given day. More frequent 'snapshots' create a more robust overall picture of phenology.

The total number of visits recorded between 2012 and 2019 was 360 on 12 Metro sites. The greatest number of visits occurred at Cooper Mountain Nature Park, with 105 visits during the eight-year period (Figure 3). Frequency of visits at Cooper Mountain were well-distributed throughout this period. The number and frequency of visits at Cooper Mountain is aligned with Metro's ambitious restoration goals for Cooper Mountain (Cooper Mountain Master Plan, 2005), as well as the rich flora of the site. Peace Cove Fen and Graham Oaks Nature Park recorded the next greatest visits from 2012 to 2019. Field visits at Peach Cove Fen are consistently distributed over the eight-year period and reflect the scientific interest in the rich herbaceous layer of the site. The profuse number of visits at Graham Oaks however, is more likely due to the efforts of two committed volunteers during 2014 and 2015 who lived adjacent to the park. The majority of data-collection at Graham Oaks took place during these years. 


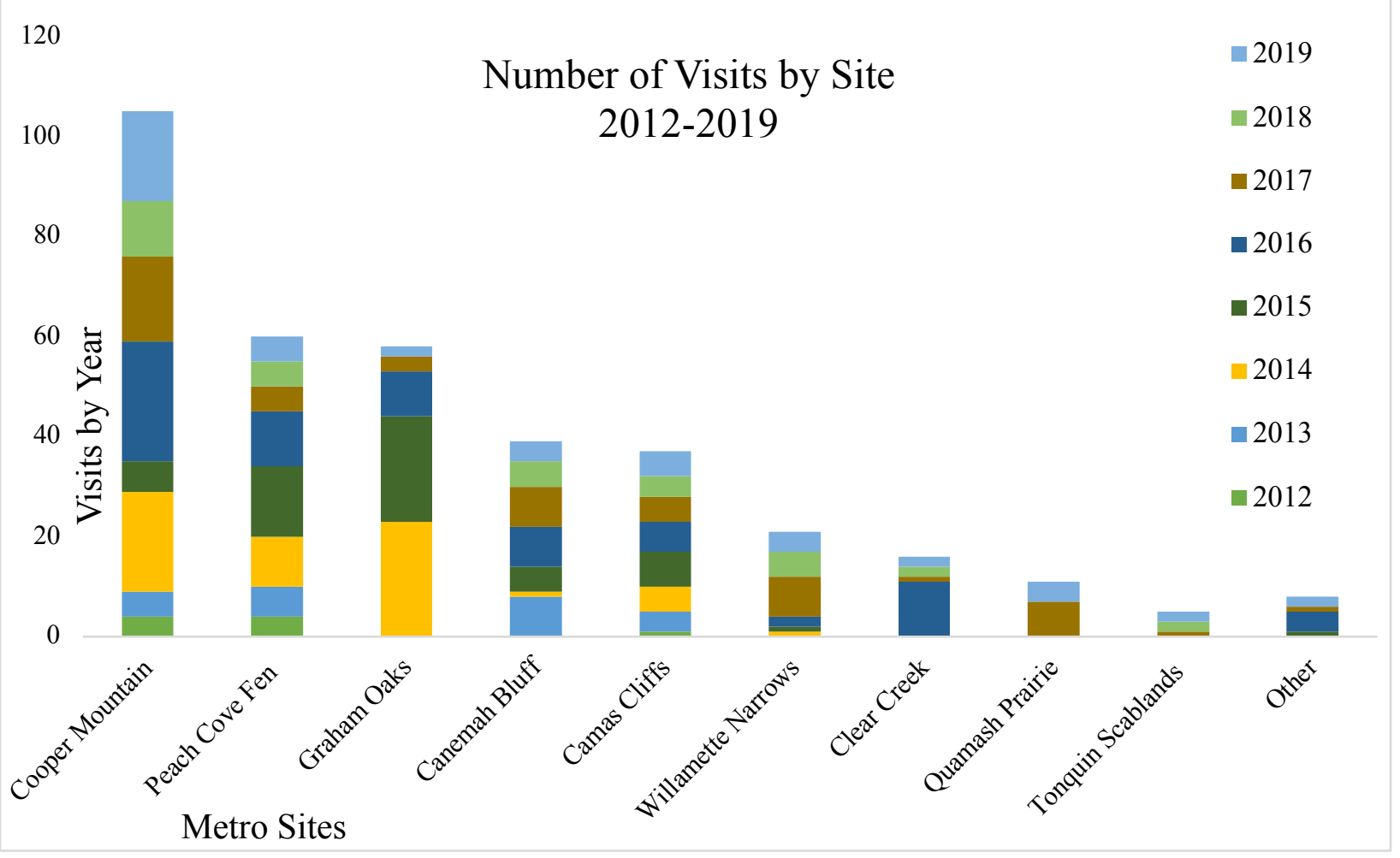

Figure 3. Cooper Mountain received the most phenology field visits between 2012 and 2019, followed by Peach Cove Fen and Graham Oaks. 'Other' refers to Heritage Pine, Mount Talbert, and Pecan Creek. The color breakdown by year shows the consistency of visits over the eight-year period. While Graham Oaks received numerous visits, they were largely concentrated during two years.

Clear Creek, Heritage Pine, Mount Talbert, Quamash Prairie, Pecan Creek and Tonquin Scablands are among the least represented sites for field visits during this time period. A number of these sites are small, less diverse, relatively new to the Metro portfolio, or not prioritized for phenology data collection, which largely contribute to their minor representation in the data. It is difficult to determine whether these sites are 'adequately' represented given these factors, and may require additional inquiry into management goals and previous site assessments, including floristic surveys. Sites previously identified as supporting numerous species or rare populations should be prioritized for phenology data collection field visits.

Next, I examined the mean observed species per year at each Metro site (Figure 4). This measure can help identify which sites are best represented by the phenology data in terms of diversity of species captured in the data. Following a comprehensive floristic study to identify species inhabiting a site, gathering phenology data on a greater number of species enriches our understanding of the plant communities that grow in a given location. Here, the greatest mean observed species were recorded during the study period at Cooper Mountain, totaling 39 species in 6 years. Peach Cove Fen and Canemah Bluff were also well-represented in the phenology data with 36 and 34 species captured, respectively. 


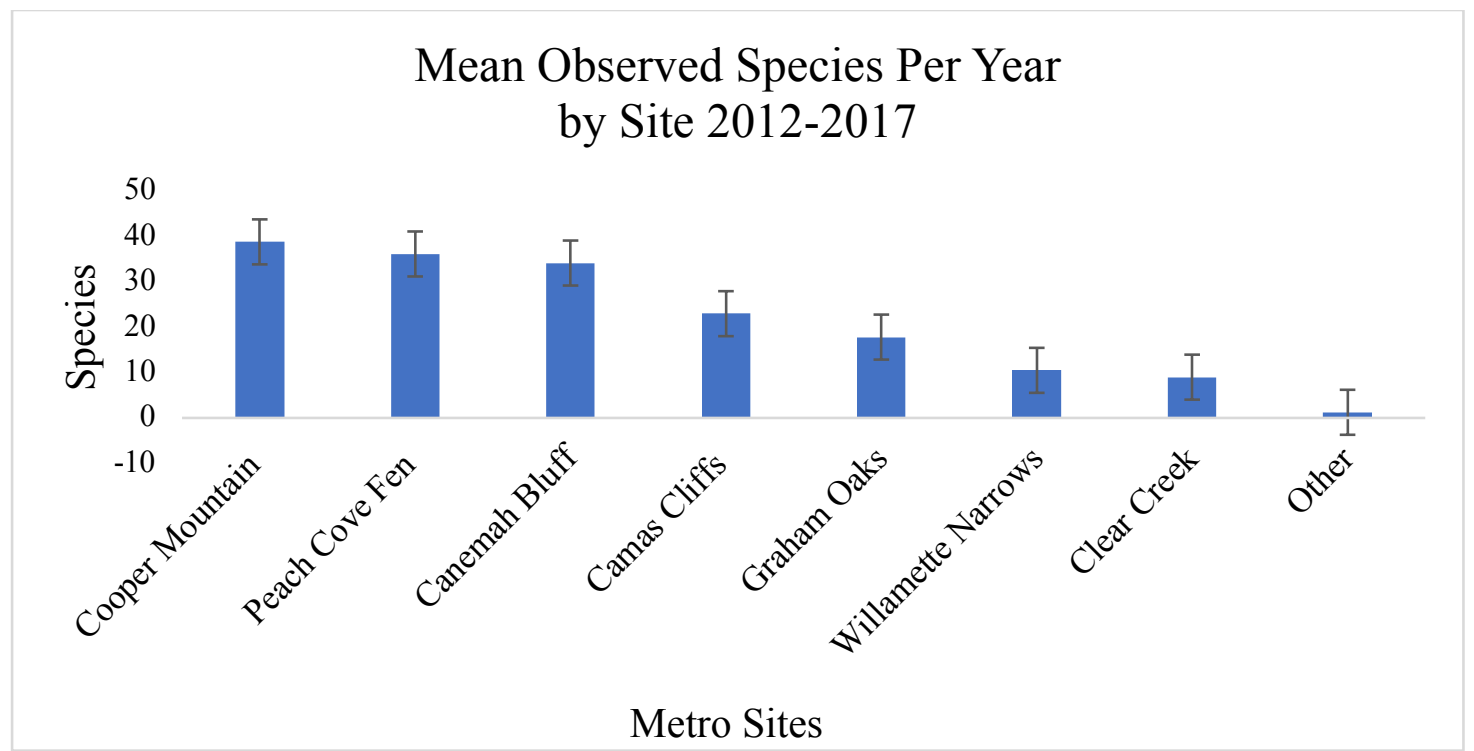

Figure 4. Mean observed species per year by site, from 2012-2017. 'Other' refers to Heritage Pine, Mount Talbert, Pecan Creek and Tonquin Scablands.

Again, it is difficult to quantify whether a site is adequately represented in the phenology data since each site differs in size and ecology. Moreover, not all sites have received a recent floristic study to evaluate species richness. Without the guide of baseline species richness, it is difficult to know if 'adequate' phenology data collection has been achieved at a particular site. Other factors also determine whether a site should be prioritized in data collection, such as the presence of rare populations and specific management goals. It is worth noting however that Willamette Narrows had a relatively low mean observed species in the phenology data. This site was previously the subject of a floristic survey that identified species and documented some population locations (Basey 2016) and may indicate the site is not adequately represented by phenology data during this study period. As resources allow, it would be beneficial to conduct comprehensive floristic studies on Metro properties to update species lists and to identify properties best suited for concentrated field studies.

What species are most consistently represented in the phenology data from 2012-2017?

Are there any significant gaps in species or functional groups represented in the data?

To answer these questions, I looked for trends by aggregating the data in multiple ways: by species as well as two types of functional groups: growth habit and life-history strategies.

\section{Species}

The phenology data of 130 forb and graminoid species were captured between 2012 and 2017. The species with the greatest mean observations per year at all combined sites was Delphinium leucophaeum (Figure 5). Given its status as a state and federally listed species of concern and a 
Metro priority for preservation and re-establishment, it is encouraging to see D. leucophaeum so robustly represented. Other species that are most consistently represented in the phenology data from 2012- 2017 are Dichelostemma congestum, Camassia quamash and Triteleia hyacinthina. Interestingly, Vancouveria hexandra, Osmorhiza chilensis and Claytonia siberica are also among the species most consistently represented in the phenology data. While all three are among Metro's long list of priority species, they are not included in Metro's short list of high-fidelity oak species, and considered less critical for conservation. Their extensive data collection is likely the result of ambitious volunteer efforts at one Metro site (Graham Oaks Nature Park).

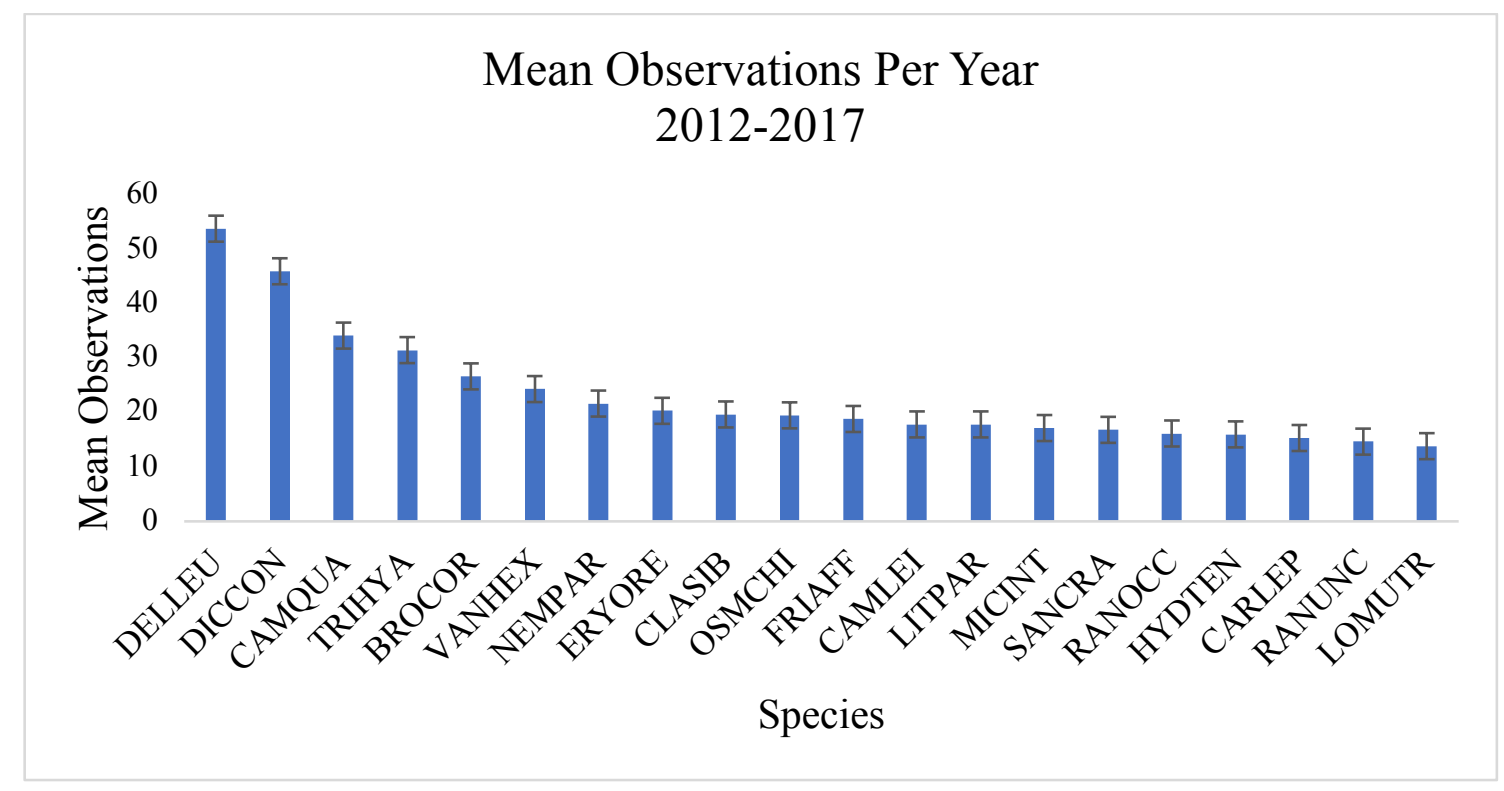

Figure 5. Mean observations between 2012 and 2017 of the top 20 species: Delphinium leucophaeum, Dichelostemma congestum, Camassia quamash, Triteleia hyacinthina and Brodiaea coronaria received the most phenology observations during this time period.

There were numerous species with little phenology data collected during the study period (57 species with 2-9 observations and 43 species with only one observation. Species with only one observation were removed from the data set, following parameters previously described) (Figure 6). These gaps represent the ambitious number of species Metro has attempted to collect data on during the study period. Limited resources make the task of sufficiently capturing data on such a large number of species difficult. Therefore, I identified the most significant gaps in species represented in the data as those aligned with Metro's short-list of priority species (Appendix A, Table 1). Here, 21 species identified as high-fidelity oak species of conservation interest are not represented in the phenology data. It is important to note that several of these species had a single observation (and were therefore removed from this analysis) or are species identified in past floristic surveys yet never located again during routine field visits. It is difficult to include all species of conservation interest in phenology studies, yet identifying gaps in the data will help determine future phenology data collection priorities. 


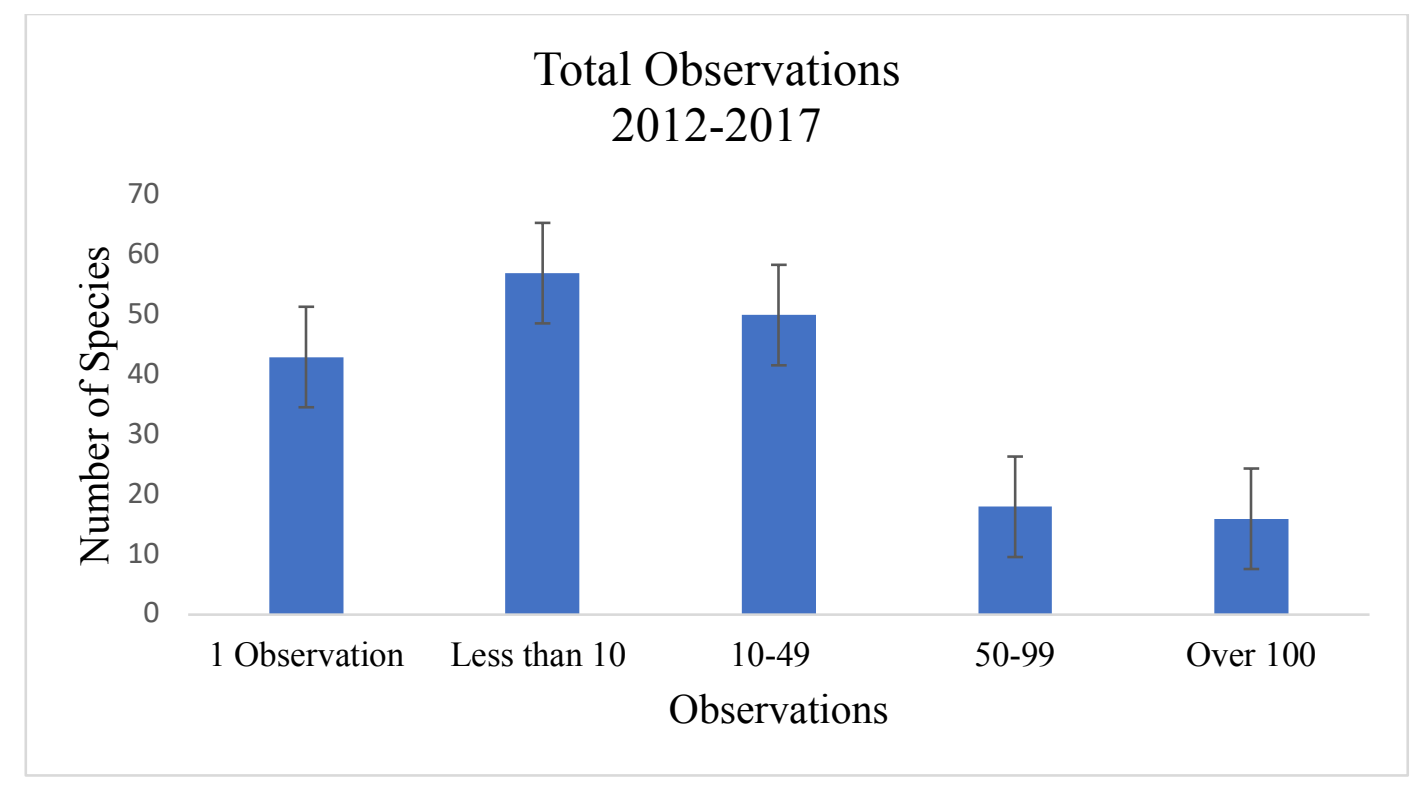

Figure 6. Sixteen species received over 100 observations during the study period. An additional 18 species received 50-99 observations, 50 species received 10-49 observations and 57 species received 2-10 observations. Forty-three species with only one observation were omitted from this analysis.

\section{Functional Groups}

To identify gaps in phenology data collected on functional groups, the data were aggregated in two ways: by growth habit (forbs and graminoids) and by life-history strategy (annuals and perennials). Functional groups offer insight into the ecological roles and community structure of an associated system. Given that climate change is predicted to profoundly impact fragile ecosystems, gathering long-term data on functional groups can help identify vulnerabilities within a system.

\section{Growth Habit: Forbs and Graminoids}

'Graminoids' are a functional group containing sedges, rushes and grasses from the families Cyperaceae, Juncaceae and Poaceae. The functional group 'Forbs' consists of all herbaceous (nonwoody) flowering plants that are not 'Graminoids' and thus do not have a grass-like growth habit. While the majority of phenology data collected during the research period focus on forbs (Figure 7), answering research questions pertaining to climate change will require a closer look at graminoids. Grasslands will likely experience dramatic changes in plant community structure, according to climate change projections (Pfeifer-Meister et al., 2013, Bachelet et al. 2011). For these reasons it would be advantageous to increase the data collection on graminoids to close this research gap. During the research period 2012-2017, graminoids were not represented among species with 100 or more observations. 


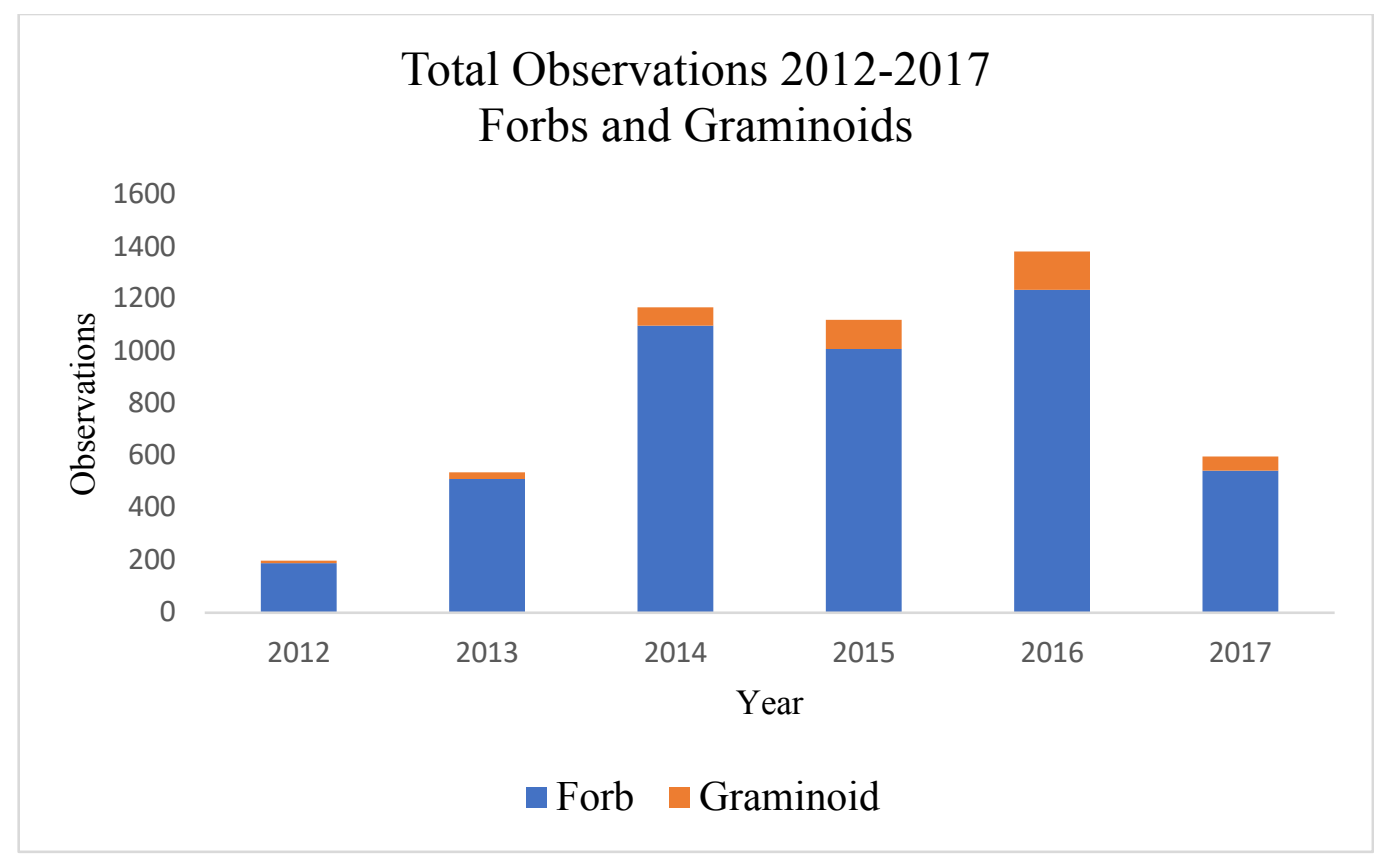

Figure 7. The majority of phenology data collected from 2012-2017 were from the forb functional group. Collecting more data on graminoids would help identify changes in plant community structure over time.

\section{Life History Strategy: Annuals and Perennials}

Plants benefit from each type of life-history strategy. Differences in the phenology of annual and perennial taxa can offer advantages depending on environmental factors (Fitter and Fitter 2002). Differences between annuals and perennials may also impact how members of each functional group respond to climate change. Short-lived species may be more susceptible to climate fluctuation than long-lived species, with risk of significant impact to reproduction and survival (Morris et al. 2008). For these reasons, it is critical to give particular attention to field observations of annual taxa. Most species of conservation interest in oak systems are perennials, therefore the majority of phenology data collected during the research period are taxa with a perennial lifehistory strategy (Figure 8). In addition, perennial taxa are better suited for amplification-- an important strategy for conservation and restoration implemented by Metro's Native Plant Center. Selecting species for amplification largely dictated past phenology data collection. However, going forward, it would be useful to identify annual taxa to ensure that consistent data are collected on plants of both types of life history strategy. Plagiobothrys, Nemophila and Plectritis are among the notable taxa found on Metro properties with an annual growth pattern. Prioritizing these and other annual species will prevent data gaps in functional groups and allow research questions concerning the effects of climate change on oak plant communities to be answered more fully. 


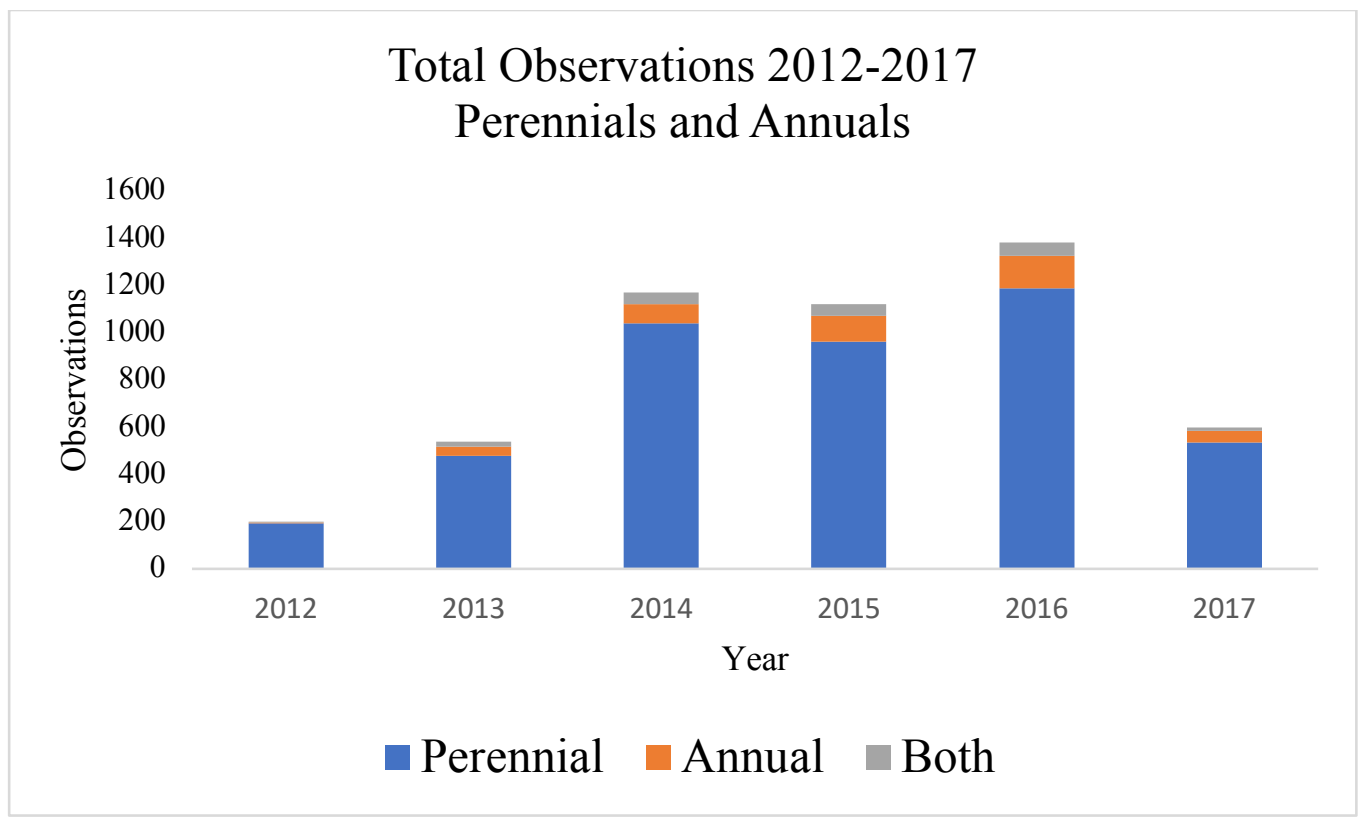

Figure 8. The majority of phenology data collected from 2012-2017 were from taxa with a perennial growth cycle. Annual taxa are particularly vulnerable to climate change stress and should be prioritized in future data-collection efforts.

During which years have volunteers made the greatest contribution to phenology data collection? (Field Visit Staffing 2012-2019)

Data collection on field visits is performed by either Metro staff, volunteers or a collaboration of both staff and volunteers (Figure 9). 'Visits' data document who was present on a field visit. By summarizing 'Visits' data, we can observe trends in staffing during the past eight years. These data may be useful in maximizing future volunteer efforts. Evaluation of 'Visits' data reveals that 2014 through 2016 were particularly strong years for volunteers. Volunteers made the greatest contribution to phenology data collection during this time and worked independently more than all other years combined. 2014 through 2016 also coincided with years in which volunteers were assigned to a specific Metro site to gather phenology data. Data from 2019 show volunteer contribution down considerably, compared to previous years. To maximize future volunteer efforts, it would be useful for Metro to clarify the long-term objective of volunteer involvement in the plant conservation program. Recruiting and training volunteers requires considerable staff effort. Strategically focusing volunteer efforts will be a meaningful asset to the program. 


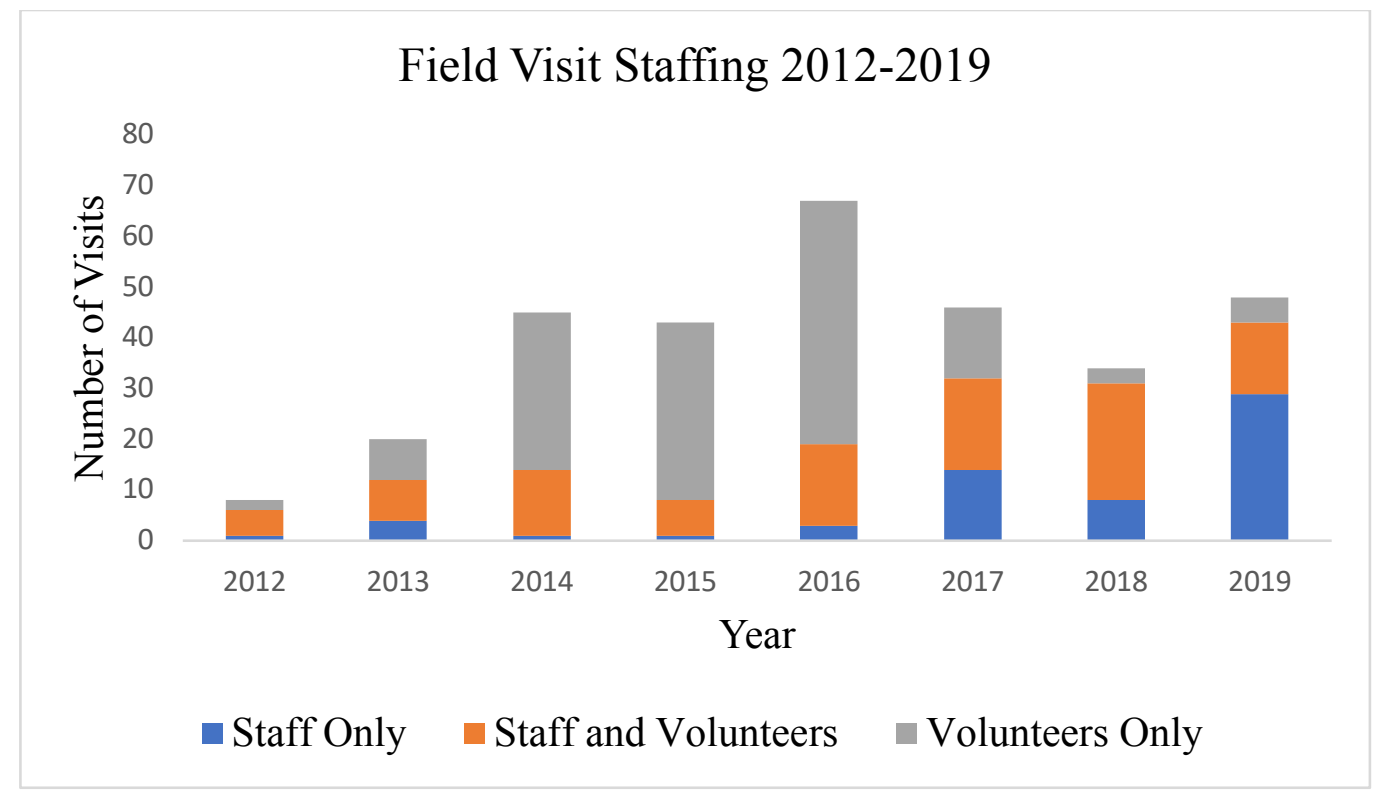

Figure 9. Staffing for field visits between 2012 and 2019. The years of 2014 through 2016 were productive for volunteers working independently, while field visits in 2019 were predominantly staffed by Metro scientists.

\section{Part 1: Evaluating Metro's Existing Plant Phenology Data and Methods}

a. $\quad$ Metro's Current Phenology Data Collection Methods 2012-2017

Through the process of summarizing Metro's existing phenology data, I evaluated the methods by which the data were collected. While the original purpose of Metro's phenology data-collection was to track long-term phenology trends, limitations in data collection methods have made such analysis difficult. Here, I address two research questions created for this project that could not be answered given gaps in the data. I outline the limitations in methodology that prevent a robust analysis, based on personal communication with Dr. Yangdong Pan, an instructor of environmental statistical analysis at Portland State University (2019).

The original research questions removed from analysis are as follows:

Question 4: Are there observable changes in phenology, particularly in flowering time and length of time between flowering and ripe seed, in species or functional groups from 2012-2018?

Question 5: Does phenology differ across sites? Can we observe differences in flowering time of the same species at different sites?

Phenology data was collected on numerous field visits during the research period. Selecting dates for field visits was largely based on staff and volunteer availability and occasionally the weather. As a result, field visits to specific sites, waypoints and plant populations have not followed a 
consistent schedule throughout the growing season, making it difficult to accurately capture the onset of phenophases.

These limitations prevent a robust analysis of the data to quantify change in plant phenology over time. We cannot confidently evaluate whether flowering time and length of time between flowering and ripe seed has changed in certain species or functional groups. The same inconsistencies in data collection prevent an accurate comparison of phenology timing across sites as well. Going forward, the goal is to standardize methods to make such analysis possible.

To quantify change in phenology, data-collection methods in the field as well as the timing of visits must be consistent. A notable limitation to Metro's data-collection methods was identified during this evaluation. On field visits, portions of the data collection form were frequently left blank. This was particularly true of taxa identification, in which a plant was identified to genus but not species. Insufficient data resulted in the removal of numerous data points from this analysis. To generate usable long-term data and to maximize returns on field visits, it is essential that all fields on the data collection form are filled. Highlighting this point during volunteer trainings would be beneficial (Mowbray 2020).

It should be emphasized that the greatest strengths of the data collection methods were the ability of Metro staff and volunteers to persevere and adapt. They have continued to collect phenology data each year in spite of limited resources and for staff, the need to balance their time across many pressing aspects of their job. Every year, Metro staff rethinks their methods and considers ways to accomplish data collection goals more efficiently. The objective of recommendations in the following section is to provide a framework for future adaptation.

\section{Part 2: Recommendations for Future Phenology Data Collection and Sharing}

To inform recommendations for future phenology data collection and sharing, I communicated with numerous regional and national scientists and practitioners familiar with plant phenology. Their insight and overwhelming support of this project guided many of the recommendations outlined in this report.

Currently, Metro's field data collection serves two purposes: to monitor species for population change in Oregon white oak habitat and to monitor species for a change in phenology. Monitoring for population change includes locating and assessing populations for annual seed collection and confirming the persistence of difficult to find populations, such as Nemophila menziesii. Collectively, tasks involving population change are considered 'Special Projects.'

First and foremost, it would be advantageous for Metro to tease apart the research objectives of phenology data collection with those of 'Special Projects.' This will allow phenology to be 
monitored more frequently at far fewer sites (Denny 2020). To do so, the objective of future field visits should be clearly defined as either 'Phenology' or 'Special Projects.' An annual review of 'Special Projects' data collected each year would ensure that populations are not being overcollected from and allow modification of target species for future seed collection.

Which species are the greatest priority for Metro to focus their future phenology data collection?

\section{a). Species Selection}

To create sustainable, reproducible methods for phenology data collection, it is essential that Metro reduce the number of species on which they collect phenology data (Harrington 2020). Currently, nearly 130 species have recorded data from 2012 to 2017. Maintaining frequent, consistent data collection on this number of species would be difficult to achieve. When considering which species to preserve on the list, there are a number of factors to take into account.

\section{Characterizing Oregon White Oak Habitat}

To begin, Metro should prioritize species that characterize the ecology of a site (Elmendorf et al. 2016). Scientists at Metro previously established a list of 73 high and medium-fidelity plant species of oak habitat based on research and recommendations by local scientists and conservation practitioners. High fidelity means these species have a high association with oak habitat and generally are not found growing elsewhere (Basey 2020). Selecting species already vetted as high and medium-fidelity will ensure that the unique ecology of regional oak systems will be accurately represented.

\section{Aligning with Historic Data}

In addition, Metro should consider aligning study species with historic data of Wilbur Bluhm. Horticulturist Wilbur Bluhm began collecting weekly phenology data on numerous species growing in the Willamette Valley in the 1960s (Wilbur L. Bluhm Plant Phenology Study 2020). These data are an invaluable record of change in phenology of local flora and used in scientific research to understand the effects of climate change in our region (Lindh and Bluhm 2018). While the majority of his study subjects are cultivated species, Bluhm collected phenology data on a select number of native species, including forbs. To dovetail with Bluhm's historic data, Metro should preserve all species on their data-collection list that overlap with Bluhm's (Guerrant 2020), of which there are sixteen (Appendix A, Table 2). In addition to these sixteen species of forbs, I recommend that Metro begin collecting phenology data on Quercus garryana, the foundation species within Oregon white oak systems. Quercus garryana is among the research species of Wilbur Bluhm as well as the National Phenology Network and OSU Extension's 'Oregon Season Tracker' phenology monitoring program. By doing so, Metro can make a meaningful contribution to a larger, historic database. 


\section{Identifying Vulnerable Clades}

An additional consideration for species selection is the research of Charles Willis et al. (2008) on phylogenetic patterns of species loss associated with climate change. Using a phenology data set collected by Henry David Thoreau and others over a period of 150 years, Willis explores how temperature-driven plasticity of flowering-time is a shared trait among closely related species. Taxa that can adjust flowering-time to temperature show patterns of persistence while taxa with rigid flowering-times exhibit a significant decrease in abundance. Willis identifies clades most vulnerable to temperature variation (such as early spring onset) associated with climate change. This research has strong implications for predicting patterns of species loss and informing future conservation strategies. It is highly recommended that Metro continue collecting phenology data on species identified by Willis et al. as among the vulnerable clades (Kaye 2020). Currently, there are 52 species that match these specifics (Appendix A, Table 3). To avoid bias toward finding phenological change in sensitive species, it is also recommended that Metro monitor taxa not identified as sensitive in the findings of Willis et al. Numerous families on Metro's list of high and medium fidelity oak species are considered relatively less sensitive and would provide a research balance (Guerrant 2020).

\section{Invasive Species as a Driver of Ecological Change}

Invasive species are considered one of the most significant threats to North American ecosystems (Blossey 1999) and acknowledged regionally as a key factor in the decline of Oregon white oak habitat and associated native species (Dennehy et al. 2011). Research indicates that invasive species exhibit greater phenological plasticity in response to temperature, which may contribute to invasion success in grassland systems (Wolkovich and Cleland 2012, Zettlemoyer et al. 2019). This is of particular concern for non-native annual grasses in ecoregions of the Pacific Northwest, with potential to alter plant community structure and ecosystem function (Pfeifer-Meister et al. 2016).

Monitoring the phenology of exotic species helps predict invasion patterns in sensitive habitat and informs adaptive management strategies. Practitioners can leverage the difference in phenology between native and exotic species with management, such as applying herbicide at opportune times (Kaye 2020). Understanding the phenology of invasive species will support efforts to mitigate the potentially catastrophic effects of exotic invasions (Morellato et al. 2016) which are predicted to increase with climate change (Pfeifer-Meister et al. 2016). For these reasons, selecting key exotic species - particularly short-lived species (Maze 2020), including annual grasses - for phenology monitoring will enhance our understanding of a major driver of ecological change.

In summary, when Metro selects species for future phenology data-collection, the following factors are deemed most critical: 
- High and medium-fidelity species that best characterize the plant ecology of Oregon white oak habitat

- Native species of the Willamette Valley included in William Bluhm's historic phenology data set

- Species within clades identified by Willis et al. as vulnerable to temperature variation

- Key exotic species (particularly exotic annual grasses)

Which locations are best-suited for Metro to focus their future phenology data collection?

\section{b). Phenopoint Selection}

To create a system of sustainable, reproducible data collection, it would be advantageous for Metro to reduce the number of phenopoints they currently monitor (Denny 2020). A phenopoint is a specific location identified for phenology data collection. Presently, 40 phenopoints have been identified as locations where species of interest grow. After reviewing the current species list and removing those not aligned with criteria outlined in the previous section (Species Selection), phenopoints can be honed to reflect fewer species. To maximize efficiency, the greatest number of species should be represented in the fewest number of points.

Factors such as microclimate (Ward 2018) and elevation (Ziello 2009) can greatly influence local plant phenology. As such, it is essential to understand the environmental conditions where data sampling occurs, in order to decouple these effects from larger climate trends. When selecting phenopoints, several factors must be taken into account. Species richness, efficient species capture (phenopoints that represent the most species in the fewest points), accessibility and environmental conditions are all important factors. Here, I have created GIS maps and tables of previously selected phenopoints that describe the following four environmental attributes: slope, aspect, elevation and soil type (Appendix B). Aspect and elevation both contribute to microclimate, while slope and soil type offer additional information about potential growing conditions.

The intention of these maps and associated table is to give an overview of the environmental conditions of the five properties where phenopoints are located. Going forward, Metro staff can refer to these baseline conditions to look for trends in phenology across sites that may be explained by these attributes. In the future Metro staff may also decide to use environmental factors to guide phenopoint selection as a way to better understand the phenology of a given location or to inform the selection of 'discovery zones': areas targeted for 'scouting' field research.

Accessibility must also be considered when selecting locations for phenology data collection. Preferably, phenopoints are positioned relatively near a road or trail. Phenopoints are grouped in proximity to allow one field visit to reach several phenopoints. For this reason, phenopoints should be concentrated on a handful of Metro properties rather than dispersed over many. Currently, 
phenopoints are clustered on five Metro properties (Figure 10). Expanding the number of properties for phenology data collection is not advised.

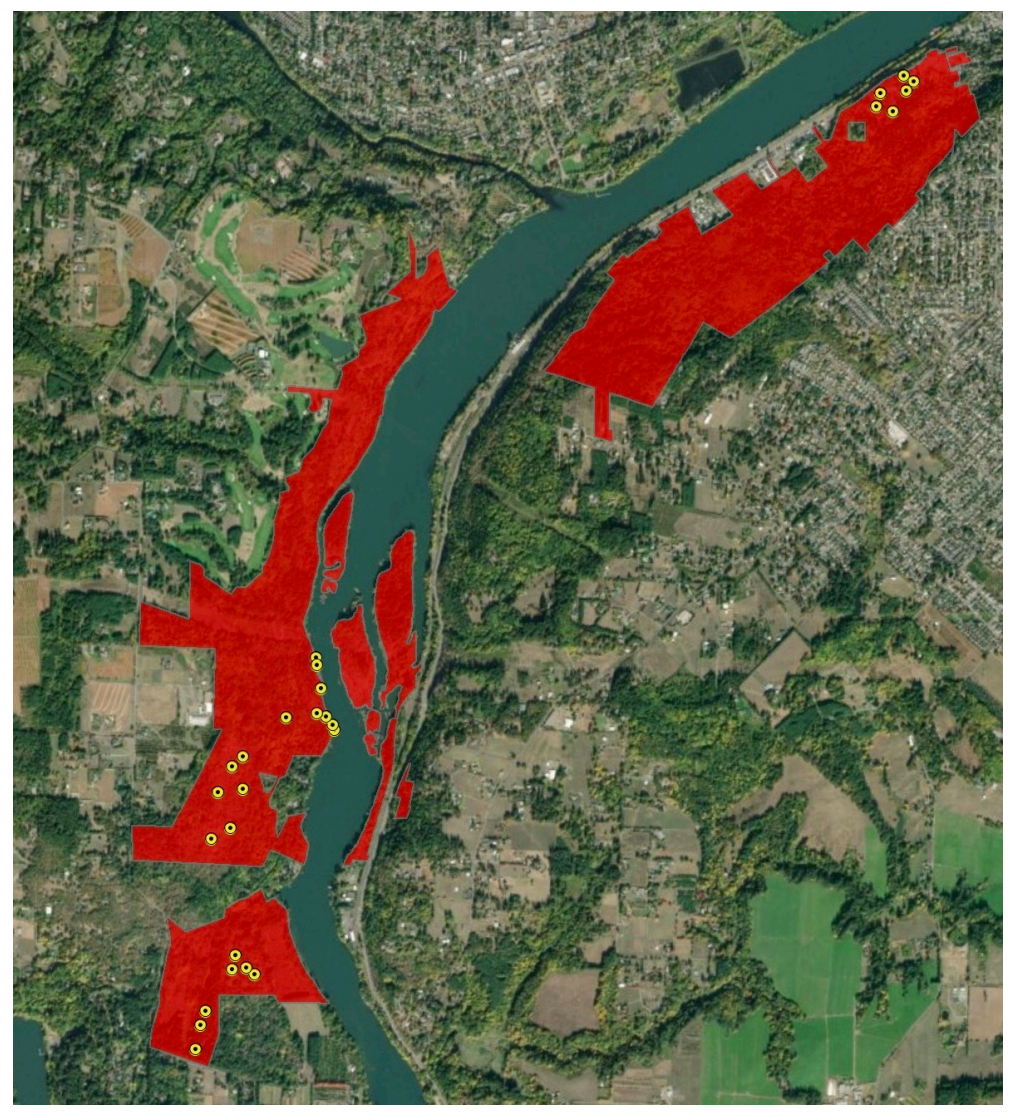

Figure 10. Four of the five Metro sites currently containing phenopoints: Peach Cove Fen, Camas Cliffs, Willamette Narrows and Canemah Bluff. (Cooper Mountain is not pictured).

It may also be helpful to use unobtrusive permanent field markers to designate a phenopoint. Doing so will make it easier to return to a particular point each year. Please see Appendix C for recommendations on permanent markers that will not attract the attention of wildlife and humans or interfere with management practices such as mowing and prescribed burns.

In summary, Metro should consider the following factors when selecting phenopoints for future phenology data-collection efforts:

- High species richness

- Efficient species capture: representing all of the selected study species in the fewest number of phenopoints

- Accessibility to roads and trails

- Environmental conditions: selecting phenopoints with well-understood environmental conditions (such as slope, aspect, elevation and soil type) to allow these factors to be separated from climate influences on phenology 


\section{c). Data-Sharing with Other Organizations}

How can Metro increase the impact of their monitoring efforts through data sharing with other organizations?

Addressing the regional and global conservation issues of our time will require unprecedented collaboration. Phenology data collected on Metro properties is not only an important asset for Metro's conservation plan, but holds potential to support broader research on a larger scale. As a leader in urban conservation, Metro is poised to make a meaningful scientific contribution by sharing phenology data with regional and national organizations. Data-sharing will benefit the common goal of conservation and create avenues for collaboration with other scientists and conservation practitioners (Rosemartin 2013).

\section{The USA National Phenology Network}

One of the major challenges of sharing phenology data is the disparate language and metrics used to describe the research (Stucky et al. 2018). To overcome this barrier, efforts are being made to standardize protocol for phenology data collection.

Established in 2007, The USA National Phenology Network (USA-NPN) is a repository of openaccess phenology data, both current and historic (USA-NPN 2020). The organization is structured to encourage scientific collaboration and provide resources to engage citizen scientists. To support these goals, USA-NPN has created standardized protocols for phenology data collection of plants and animals. Scientists use these protocols to quantify the timing, length and intensity of phenophases of the study organism (Denny 2014). The protocol developed by USA-NPN is widely accepted by the scientific community and implemented by other organizations, such as The National Ecological Observatory Network (NEON) (Elmendorf et al. 2016). Metro would benefit from sharing their data with USA-NPN for the purpose of scientific collaboration and advancement (Hardison 2020, Harrington 2020).

Partnering with USA-NPN would benefit Metro in other ways as well. First, it would allow Metro to access a standard phenology data-collection protocol accepted by the scientific community. This protocol would provide a framework for Metro's data collection and support Metro's long-term data collection goals. In addition, using USA-NPN protocol would allow data to be entered directly into a mobile device in the field, through a free mobile application or a browser-based interface. This would eliminate the need to transfer data upon return from the field, and eliminate potential errors associated with this additional step. Using a mobile device rather than paper forms in the field is recommended for Metro to streamline the process of data collection and consolidation, and to reduce errors (Mowbray 2020). 
Second, partnering with the USA-NPN would provide a framework for volunteer involvement (Barnett 2020). It is well-documented that volunteer involvement in data collection can expand the scope of a project, encourage community engagement and reduce costs (Cosquer et al. 2012, McKinley et al. 2017). Following standardized protocol, volunteers can accurately identify the phenophase of a range of plants over $91 \%$ of the time (Fuccillo et al. 2015).

While volunteers have been assisting with Metro's data collection for nearly a decade, their contribution is often underutilized or requires extensive staff support to yield returns. Metro would benefit from additional infrastructure to support the strong community interest in Metro's plant conservation program. The USA-NPN's 'Nature's Notebook' program provides training guidelines, educational literature and a monthly newsletter to keep volunteers connected and invested in the research project (National Phenology Network 2020). Volunteers are most committed to citizen science programs when they receive adequate training, frequent feedback, and rewards (Beaubien and Hamann 2011). The 'Nature's Notebook' program would help meet these objectives. Furthermore, using USA-NPN guidelines would allow volunteers to become well-acquainted with a specific site for data collection. Based on Metro's staffing trends in data collection from 2012-2019, the most substantial and consistent volunteer contributions occurred when volunteers were assigned to a specific site.

Lastly, a partnership with USA-NPN would allow Metro to perform meaningful analysis on their data using USA-NPN's visualization tools (Figure 11). These tools allow users to sort data in a variety of ways, create maps and time series, and overlay Parameter-elevation Regressions on Independent Slopes Model (PRISM) climate data to observe trends in climate. Access to such analysis would be an enormous asset to Metro's plant conservation program. In addition, USANPN is willing to upload Metro's previously collected data (Denny 2020), which will strengthen Metro's analysis potential.

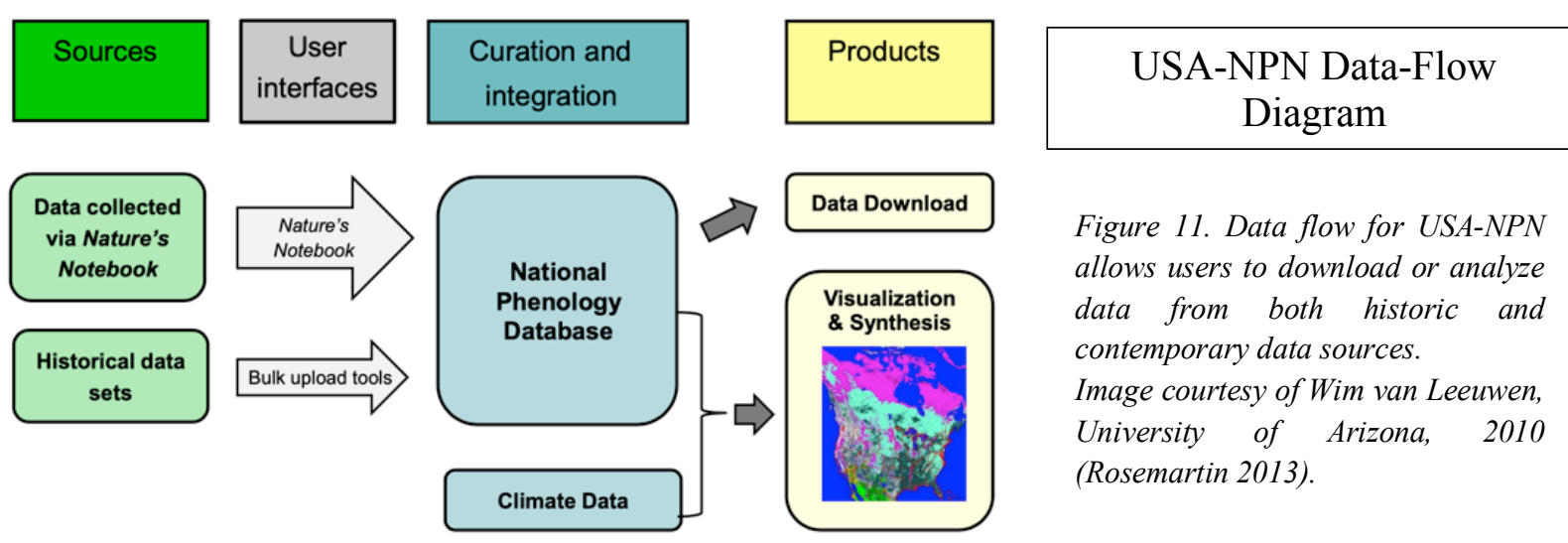

\section{Oregon Flora Project}

In association with the Oregon State University Herbarium, the Oregon Flora Project (OFP) is an invaluable regional resource of Oregon's botanical information. The OFP provides open-access 
data about Oregon vascular plants that grow without cultivation, and includes an interactive Oregon plant atlas that shows occurrence data of Oregon plants, based on herbarium specimens and field observations. Scientists and citizens are encouraged to share their observation data to increase the strength of OFP's dataset in providing a comprehensive resource documenting the occurrence of Oregon vascular plants (Oregon Flora Project 2020).

Sharing data with OFP would increase the impact of Metro's monitoring efforts by contributing to an open-access database for the benefit of regional research. Currently, OFP does not have the infrastructure to accept phenology data to supplement the Oregon plant atlas. They are however, exploring future ideas for expanding their data-submission template to include phenology data. The OFP sees great value in collecting long-term phenology data, particularly in sensitive habitats, such as wet prairies (Hardison 2020).

In the immediate future, OFP recommends that Metro share their observation data with OFP to increase the strength of the Oregon plant atlas as a significant resource for regional plant conservation. Metro's data will help document regional trends in occurrence for species of conservation interest. In addition, OFP recommends that Metro share their phenology data with the National Phenology Network. The USA-NPN is well-accepted by the scientific community and possesses the infrastructure to support large-scale collaboration. Collaboration on both regional and national scales will improve our understanding of plant community dynamics under the increasing pressures of climate change.

\section{Part 3: Creating Educational Vouchers for Metro's Teaching Herbarium}

For the final part of this project, I created scientific vouchers of 22 plant species in varying phases of phenology for Metro's teaching herbarium. The purpose of these vouchers is to provide a visual tool for Metro staff and volunteers who rely on plant identification to carry out aspects of their job in plant conservation. The vouchers will help distinguish between easily misidentified species, both native and non-native, based on recommendations from Metro associates. Preparation of specimens followed treatment outlined in The Herbarium Handbook (Bridson and Forman 2013).

I began by reaching out to seed scouts, technicians and scientists at Metro to learn what plant species (both native and non-native) are especially difficult to tell apart or most often misidentified by contractors in the field. From these recommendations, I collected 23 specimens from Metro properties over the course of six months (May through October 2019). sI collected mainly from plants growing at Metro's Native Plant Center, to reduce my impact on native plant communities on restored properties and to ensure proper identification of species. One specimen (garlic mustard) was collected elsewhere in the Portland area after I tried unsuccessfully to locate a sample on Metro properties. 
Based on feedback from staff and volunteers, I gave special attention to leaf morphology of forbs, such as Sidelcea, Alliaria and Drymocallis (Figure 12). When appropriate, the voucher labels include information about 'look-alike' species to offer additional identification guidance. This project is ongoing. Metro would benefit from augmenting their teaching herbarium and encouraging staff and volunteers to utilize this resource to strengthen plant identification skills.

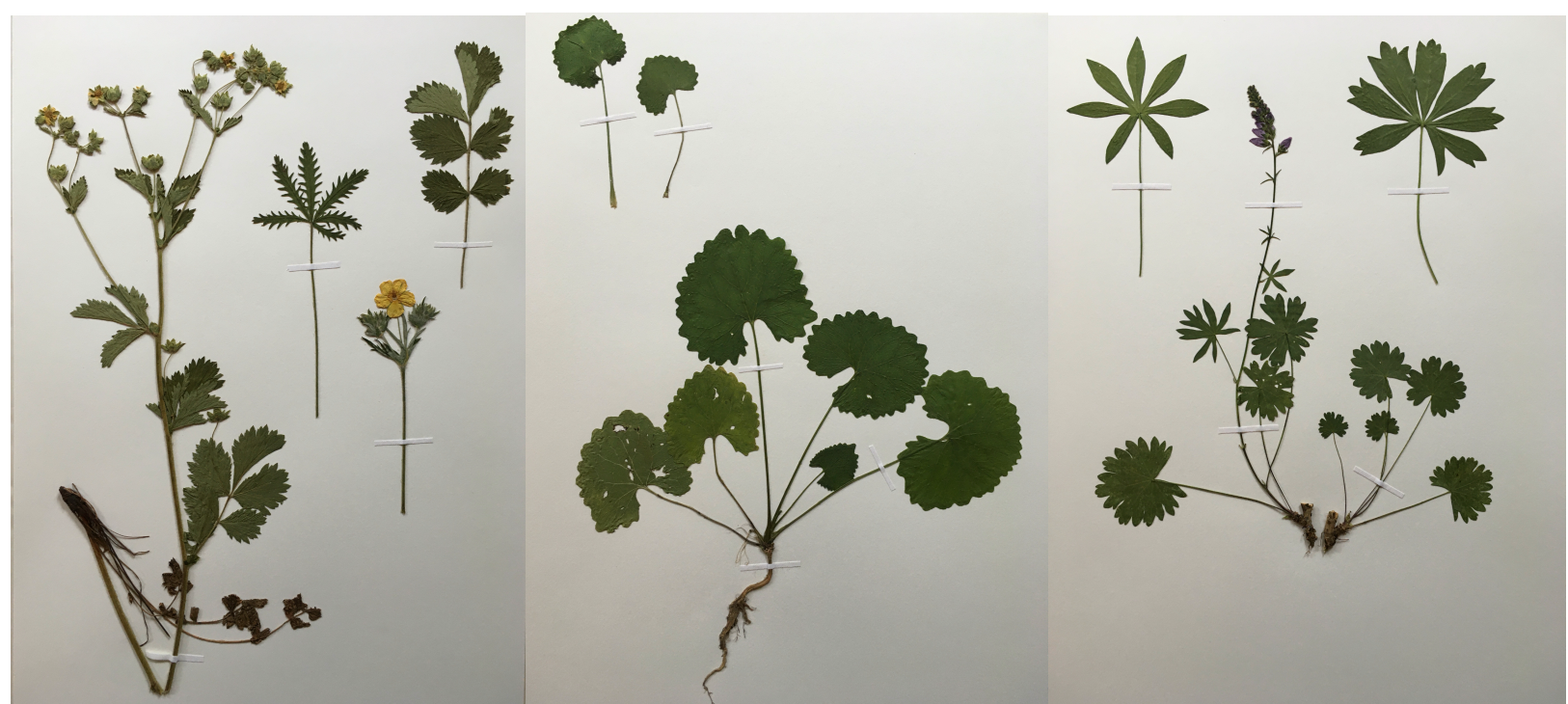

Figure 12. Scientific vouchers for Metro's teaching herbarium of Drymocallis glandulosa, Alliaria petiolata and Sidalcea nelsoniana with emphasis on leaf morphology.

\section{Areas of Future Research}

Metro would benefit from continued research in several areas initiated by this project.

1) As mentioned in the previous section, augmenting the teaching herbarium with additional voucher specimens would be an asset to Metro. Specifically, creating vouchers that document graminoid species - both native and non-native - would target a particularly difficult area in plant identification. There are numerous graminoid species of conservation interest as well as numerous exotic species that require control strategies. Creating voucher specimens of important graminoid taxa would help avoid misidentification and benefit Metro scientists, technicians and volunteers alike.

2) While the focus of this project was to improve future phenology data-collection methods, Metro would also benefit from evaluating their current field methods to monitor change in population. Standardizing and streamlining population monitoring could save resources and more accurately quantify change in population size and structure over time. 
3) A deeper analysis of environmental attributes using GIS may offer more detail for phenopoint and 'discovery zone' selection on Metro properties.

4) There is growing interest in how plant phenology may influence the invasion success of exotic species. Research on this topic may identify vulnerable native species and predict change in plant community structure of Oregon white oak systems over time. Investigation into the phenology of annual exotic grasses could be particularly useful in shaping adaptive management on Metro properties. 


\section{Cited Literature and Communication}

Adler, F. R., \& Tanner, C. J. (2013). Urban ecosystems: ecological principles for the built environment. Cambridge: Cambridge University Press.

Alverson, Edward. Natural Areas Coordinator, Lane County Parks. (January, 2020). Personal communication.

Apostol, D., \& Sinclair, M. (2006). Restoring the Pacific Northwest: the art and science of ecological restoration in Cascadia. Washington, DC: Island Press.

Bachelet, D., Johnson, B., Bridgham, S., Dunn, P., Anderson, H., and Rogers, B. (2011). Climate Change Impacts on Western Pacific Northwest Prairies and Savannas. Northwest Science, 85(2):411-429.

Barnett, LoriAnne. Education Coordinator, USA National Phenology Network. (January, 2020). Personal communication.

Basey, A. (2016). Oak and Prairie Species Conservation and Seed Banking Project 2016 Report, Oregon Metro.

Beaubien, E. G., \& Hamann, A. (2011). Plant phenology networks of citizen scientists: recommendations from two decades of experience in Canada. International Journal of Biometeorology, 55(6), 833-841.

Blossey, B. (1999). Before, During and After: The Need for Long-term Monitoring in Invasive Plant Species Management. Biological Invasions. 1: 301.

Bridson, D., \& Forman, L. (2013). The herbarium handbook. Kew: Royal Botanic Gardens.

Cavender-Bares, J. and Reich, P. B. (2012). Shocks to the system: community assembly of the oak savanna in a 40-year fire frequency experiment. Ecology, 93(8) Supplement, pp. S52-S69, 2012 by the Ecological Society of America.

Christy, J., \& Alverson, E. (2011). Historical Vegetation of the Willamette Valley, Oregon, circa 1850. Northwest Science 85:93-107.

Cooper Mountain Master Plan and Management Recommendations. (2005). Prepared by Metro Regional Parks and Greenspaces. Portland, Oregon.

Cosquer, A., Raymond, R., \& Prevot-Julliard, A. (2012). Observations of Everyday Biodiversity: A New Perspective for Conservation? Ecology and Society, 17(4).

Crimmins, T. M., Crimmins, M. A., Gerst, K. L., Rosemartin, A. H., \& Weltzin, J. F. (2017). USA National Phenology Network's volunteer-contributed observations yield predictive models of phenological transitions. Plos One, 12(8).

Culley T. (2013). Why vouchers matter in botanical research. Applications in Plant Sciences, 1(11).

Davies, T. J., Wolkovich, E. M., Kraft, N. J., Salamin, N., Allen, J. M., Ault, T. R., . . Travers, S. E. (2013). Phylogenetic conservatism in plant phenology. Journal of Ecology, 101(6), 1520-1530.

Dennehy, C., Alverson, E. R., Anderson, H. E., Clements, D. R., Gilbert, R., \& Kaye, T. N. (2011). Management Strategies for Invasive Plants in Pacific Northwest Prairies, Savannas, and Oak Woodlands. Northwest Science, 85(2), 329-351. 
Denny, E. G., Gerst, K. L., Miller-Rushing, A. J., Tierney, G. L., Crimmins, T. M., Enquist, C. A. F., ... Weltzin, J. F. (2014). Standardized phenology monitoring methods to track plant and animal activity for science and resource management applications. International Journal of Biometeorology, 58(4), 591-601.

Denny, Ellen. Monitoring Design \& Data Coordinator, USA National Phenology Network. (January, 2020). Personal communication.

Dunwiddie PW, Bakker JD (2011) The future of restoration and management of prairie-oak ecosystems in the Pacific Northwest. Northwest Science 85:83-92.

Elmendorf, S. C., Jones, K. D., Cook, B. I., Diez, J. M., Enquist, C. A. F., Hufft, R. A., ... Weltzin, J. F. (2016). The plant phenology monitoring design for The National Ecological Observatory Network. Ecosphere, 7(4).

Fitter, A. and Fitter, R. (2002). Rapid Changes in Flowering Time in British Plants. Science, 296 (5573): 16891691.

Fuccillo, K. K., Crimmins, T. M., Rivera, C. E. D., \& Elder, T. S. (2014). Assessing accuracy in citizen sciencebased plant phenology monitoring. International Journal of Biometeorology, 59(7), 917-926.

Garibaldi, A., \& Turner, N. (2004). Cultural Keystone Species: Implications for Ecological Conservation and Restoration. Ecology and Society, 9(3).

Guerrant, Ed. Director (Retired), Rae Selling Berry Seed Bank \& Plant Conservation Program, Department of Environmental Science and Management, Portland State University. (January, 2020). Personal communication.

Hanski, I., \& Ovaskainen, O. (2002). Extinction Debt at Extinction Threshold. Conservation Biology, 16(3), $666-673$.

Hardison, Linda. Director, OregonFlora, Department of Botany \& Plant Pathology, Oregon State University. (February, 2020). Personal communication.

Harrington, Constance. Emeritus Scientist, Forest Service, Pacific Northwest Research Station. (January, 2020). Personal communication.

Hulse, D., S. Gregory, and J. Baker. "Willamette River Basin: Trajectories of environmental and ecological change, a planning atlas." Oregon State University Press, Corvallis, Oregon 97333 (2002): 182.

Kaye, Tom. Executive Director, Institute for Applied Ecology. Associate Professor, Department of Botany \& Plant Pathology, Oregon State University. (January, 2020). Personal communication.

Lindh, B. C., Mcgahan, K. A., \& Bluhm, W. L. (2018). Changes in urban plant phenology in the Pacific Northwest from 1959 to 2016: anthropogenic warming and natural oscillation. International Journal of Biometeorology, 62(9), 1675-1684.

Maze, Dominic. Biologist, Invasive Species Coordinator, City of Portland Environmental Services. (February, 2020). Personal Communication.

Mckinley, D. C., Miller-Rushing, A. J., Ballard, H. L., Bonney, R., Brown, H., Cook-Patton, S. C., ... Soukup, M. A. (2017). Citizen science can improve conservation science, natural resource management, and environmental protection. Biological Conservation, 208, 15-28.

Morellato, L., Alberton, B., Alvarado, S., Borges, B., Buisson, Camargo, M., Cancian, L., Carstensen, D., Escobar D... Peres, C. (2016). Linking plant phenology to conservation biology. Biological Conservation, 195, $60-72$. 
Morris, W. F., Pfister, C. A., Tuljapurkar, S., Haridas, C. V., Boggs, C. L., Boyce, M. S., ... Menges, E. S. (2008). Longevity Can Buffer Plant And Animal Populations Against Changing Climatic Variability. Ecology, $89(1), 19-25$.

Mowbray, Al. Associate GIS Specialist, Research Center, Oregon Metro. (January, 2020). Personal communication.

Oregon Department of Fish and Wildlife. (2016). Oregon Conservation Strategy. Oak Woodlands. Retrieved from https://www.oregonconservationstrategy.org/strategy-habitat/oak-woodlands/. (January 14, 2020).

Oregon Department of Agriculture (n.d.). Delphinium leucophaeum and Sidalcea nelsoniana. Retrieved from https://www.oregon.gov/ODA/shared/Documents/Publications/PlantConservation/DelphiniumLeucophaeumPr ofile.pdf.

https://www.oregon.gov/oda/shared/Documents/Publications/PlantConservation/SidalceaNelsonianaProfile.pdf (January 14, 2020).

Pan, Yangdong. Professor, Department of Environmental Science and Management, Portland State University. (November 2019). Personal communication.

Parmesan, C. (2006). Ecological and Evolutionary Responses to Recent Climate Change. Annual Review of Ecology, Evolution, and Systematics, 37(1), 637-669.

Parmesan, C. (2007). Influences of species, latitudes and methodologies on estimates of phenological response to global warming. Global Change Biology 13:1860-1872.

Penuelas, J. \& Filella, I. (2001). Responses to a Warming World. Science, 294(5543), 793-795.

Pfeifer-Meister, L., Bridgham, S., Little, C., Reynolds, L., Goklany, M., and Johnson, B. (2013) Pushing the limit: experimental evidence of climate effects on plant range distributions. Ecology, 94(10): 2131-2137.

Pfeifer-Meister, L., Bridgham, S. D., Reynolds, L. L., Goklany, M. E., Wilson, H. E., Little, C. J., Ferguson, A., \& Johnson, B. R. (2015). Climate change alters plant biogeography in Mediterranean prairies along the West Coast, USA. Global Change Biology.

Rosemartin, A. H., Crimmins, T. M., Enquist, C. A., Gerst, K. L., Kellermann, J. L., Posthumus, E. E., ... Weltzin, J. F. (2014). Organizing phenological data resources to inform natural resource conservation. Biological Conservation, 173, 90-97.

Stucky, B. J., Guralnick, R., Deck, J., Denny, E. G., Bolmgren, K., \& Walls, R. (2018). The Plant Phenology Ontology: A New Informatics Resource for Large-Scale Integration of Plant Phenology Data. Frontiers in Plant Science, 9 .

The Intertwine Alliance. (2012). Regional Conservation Strategy for the Greater Portland-Vancouver Region. A. Sihler, editor. Retrieved from www.theintertwine.org. (January 17, 2020).

Thilenius J.F. (1968). The Quercus garryana forests of the Willamette Valley. Ecology. Volume 49, No. 6, pp. 1124-1133.

USA- National Phenology Network. (n.d.) Retrieved from https://www.usanpn.org/usa-national-phenologynetwork. (December 31, 2019). 
U.S. Fish and Wildlife (n.d.) Fenders blue butterfly (lcaricia icarioides fender). Retrieved from https://www.fws.gov/oregonfwo/articles.cfm?id=149489429. (January 14, 2020).

U.S. Fish and Wildlife Service (2017). Willamette Valley Conservation Study. Retrieved from https://www.fws.gov/YourWillametteValley/Conservation_Study/WVCS_Study.pdf. (January 14, 2020).

Vesely, D. \& Tucker, G. (2004). A Landowner's Guide for Restoring and Managing Oregon White Oak Habitats. Retrieved from https://www.blm.gov/or/districts/salem/files/white_oak_guide.pdf. (January 3, 2020)

Walsh, M. K., C. A. Pearl, C. Whitlock, P. J. Bartlein, M. A. Worona. (2010). An 11,000-year-long record of fire and vegetation history at Beaver Lake, Oregon, central Willamette Valley. Quaternary Science Reviews 29:1093-1106.

Ward, S. E., Schulze, M., \& Roy, B. (2018). A long-term perspective on microclimate and spring plant phenology in the Western Cascades. Ecosphere, 9(10).

Whittington, H. R., Tilman, D., Wragg, P. D., \& Powers, J. S. (2015). Phenological responses of prairie plants vary among species and year in a three-year experimental warming study. Ecosphere, 6(10).

Wilbur L. Bluhm Plant Phenology Study. (n.d.) Oregon State University. Retrieved from http://agscilabs.oregonstate.edu/plantphenology. (January 22, 2020).

Willamette Partnership (2016). The Oak Accord. Retrieved from https://willamettepartnership.org/oak-accord/. (December 31, 2019).

Willis, C. G., Ruhfel, B., Primack, R. B., Miller-Rushing, A. J., \& Davis, C. C. (2008). Phylogenetic patterns of species loss in Thoreaus woods are driven by climate change. Proceedings of the National Academy of Sciences, 105(44).

Wolkovich, E. M., \& Cleland, E. E. (2010). The phenology of plant invasions: a community ecology perspective. Frontiers in Ecology and the Environment, 9(5), 287-294.

Zettlemoyer, M. A., Schultheis, E. H., \& Lau, J. A. (2019). Phenology in a warming world: differences between native and non-native plant species. Ecology Letters.

Ziello, C., Estrella, N., Kostova, M., Koch, E., \& Menzel, A. (2009). Influence of altitude on phenology of selected plant species in the Alpine region (1971-2000). Climate Research, 39, 227-234. 


\section{Sources for Creating Vouchers}

Bridson, D., \& Forman, L. (2013). The herbarium handbook. Kew: Royal Botanic Gardens.

Hitchcock, C. L., Cronquist, A., Giblin, D., Janish, J. R., Legler, B., Olmstead, R. G., ... Zika, P. F. (2018). Flora of the Pacific Northwest: an illustrated manual. Seattle: University of Washington Press.

Oregon Flora Project. (2020). Department of Botany \& Plant Pathology, Oregon State University. Retrieved from http://www.oregonflora.org. (January 21, 2020).

Pojar, J., MacKinnon, A., \& Alaback, P. B. (2016). Plants of the Pacific Northwest coast: Washington, Oregon, British Columbia \& Alaska. Auburn, WA, USA: Lone Pine.

Swearingen, J., C. Bargeron. (2016). Invasive Plant Atlas of the United States. University of Georgia Center for Invasive Species and Ecosystem Health. Retrieved from http://www.invasiveplantatlas.org/. (February 2, 2020).

Wisehart, L., and Kaye, T. (2008) Field Guide to Weeds of the Willamette Valley. Institute for Applied Ecology. 


\section{Appendixes}

\section{Appendix A: Tables of Plants and Environmental Attributes}

Table 1. Thirty species of forbs and graminoids identified as a conservation priority by Oregon Metro which are not represented in phenology data collected from 2012 to 2017.

\begin{tabular}{|c|c|c|c|}
\hline $\begin{array}{l}\text { SPECIES } \\
\text { CODE }\end{array}$ & TAXON & FAMILY & COMMON NAME \\
\hline LOMDIS & Lomatium dissectum & Apiaceae & fern leaved lomatium \\
\hline APOCAN & Apocynum cannabinum & Apocynaceae & common dogbane \\
\hline BALDEL & Balsamorhiza deltoidea & Asteraceae & deltoid balsamroot \\
\hline CREATR & Crepis atribarba & Asteraceae & slender hawksbeard \\
\hline GRIINT & Grindelia integrifolia & Asteraceae & Willamette Valley gumweed \\
\hline HETVIL & Heterotheca villosa var. villosa & Asteraceae & Hairy False Goldenaster \\
\hline SYMHAL & Symphyotrichum hallii & Asteraceae & Hall's aster \\
\hline CRYINT & Cryptantha intermedia & Boraginaceae & common cryptantha \\
\hline SILDOU & Silene douglasii & Caryophyllaceae & Douglas' catchfly \\
\hline SEDLAN & Sedum lanceolatum & Crassulaceae & lanceleaf stonecrop \\
\hline CARROS & Carex rossii & Cyperaceae & Ross' sedge \\
\hline TRIBIF & Trifolium bifidum & Fabaceae & notchleaf clover \\
\hline TRIOLI & Trifolium oliganthum & Fabaceae & few flowered clover \\
\hline TRIWIL & Trifolium willdenovii & Fabaceae & tomcat clover \\
\hline TRILAN & Trichostema lanceolatum & Lamiaceae & vinegar weed \\
\hline SIDNEL & Sidalcea nelsoniana & Malvaceae & Nelson's Sidalcea \\
\hline CALCIL & Calandrinia ciliata & Montiaceae & red maids \\
\hline CLARHO & Clarkia rhomboidea & Onagraceae & rhomboid clarkia \\
\hline OROFAS & Orobanche fasciculata & Orobanchaceae & clustered broomrape \\
\hline OROUNI & Orobanche uniflora & Orobanchaceae & one-flowered broomrape \\
\hline PENRYD & Penstemon rydbergii var. oreocharis & Plantaginaceae & Rydberg's penstemon \\
\hline PENSER & Penstemon serrulatus & Plantaginaceae & Cascades penstemon \\
\hline AGRHAL & Agrostis hallii & Poaceae & Hall's bentgrass \\
\hline DANSPI & Danthonia spicata & Poaceae & poverty oatgrass \\
\hline FESCAL & Festuca californica & Poaceae & California fescue \\
\hline FESIDA & Festuca idahoensis ssp. roemeri & Poaceae & Roemer's fescue \\
\hline MELSUB & Melica subulata & Poaceae & Alaska oniongrass \\
\hline NAVINT & Navarretia intertexta & Polemoniaceae & needleleaf navarretia \\
\hline NAVSQU & Navarretia squarrosa & Polemoniaceae & skunkweed \\
\hline SAXMER & Saxifraga mertensiana & Saxifragaceae & Mertens' saxifrage \\
\hline
\end{tabular}


Table 2: Recommendation for continued phenology data collection on sixteen species of forbs. These species align with data collected in the Willamette Valley by horticulturist Wilbur Bluhm for decades. In bold are species associated with at-risk clades identified by Willis et al. (2008).

\begin{tabular}{|l|l|l|l|l|}
\hline SPECIES CODE & TAXON & FAMILY & COMMON NAME & $\begin{array}{l}\text { YEARS OF DATA } \\
\text { collected by Wilbur Bluhm }\end{array}$ \\
\hline CALTOL & Calochortus tolmiei & Liliaceae & cat's ear & 15 \\
\hline CAMLEI & Camassia leichtlinii & Asparagaceae & great camas & 21 \\
\hline CAMQUA & Camassia quamash & Asparagaceae & small camas & 16 \\
\hline CLASIB & Claytonia sibirica & Montiaceae & candyflower & 20 \\
\hline DICCON & Dichelostemma congestum & Asparagaceae & ookow & 22 \\
\hline ERYORE & Erythronium oregonum & Liliaceae & Oregon fawn-lily & 22 \\
\hline HYDTEN & Hydrophyllum tenuipes & Hydrophyllaceae & Pacific waterleaf & 15 \\
\hline MAISTE & Maianthemum stellatum & Asparagaceae & false Solomon's seal & 15 \\
\hline POTGRA & Potentilla gracilis & Rosaceae & graceful cinquefoil & 17 \\
\hline PROHOO & Prosartes hookeri & Liliaceae & Hooker's fairy bells & 17 \\
\hline RANUNC & Ranunculus uncinatus & Ranunculaceae & little buttercup & 15 \\
\hline SIDCAM & Sidalcea campestris & Malvaceae & Meadow checkermallow & 16 \\
\hline TELGRA & Tellima grandiflora & Saxifragaceae & large fringecup & 18 \\
\hline TRIOVA & Trillium ovatum & Melanthiaceae & western trillium & 20 \\
\hline VANHEX & Vancouveria hexandra & Berberidaceae & white inside-out flower & 25 \\
\hline VIOGLA & Viola glabella & Violaceae & stream violet & 17 \\
\hline
\end{tabular}

Table 3. Recommendation for continued phenology data collection on fifty-two species of forbs. These species are associated with at-risk clades identified by Willis et al. (2008).

\begin{tabular}{|l|l|l|l|}
\hline SPECIES CODE & TAXON & FAMILY & COMMON NAME \\
\hline ACHMIL & Achillea millefolium & Asteraceae & yarrow \\
\hline ACTRUB & Actaea rubra & Ranunculaceae & western red baneberry \\
\hline ADEBIC & Adenocaulon bicolor & Asteraceae & pathfinder \\
\hline AQUFOR & Aquilegia formosa & Ranunculaceae & red columbine \\
\hline CALTOL & Calochortus tolmiei & Liliaceae & cat's ear \\
\hline CASTEN & Castilleja tenuis & Orobanchaceae & white paintbrush, hairy owl clover \\
\hline CIRALP & Circaea alpina & Onagraceae & enchanter's nightshade \\
\hline CLAGRA & Claria gracilis & Onagraceae & \multicolumn{2}{|l|}{ slender godetia } \\
\hline CLAAMO & Clarkia amoena & Onagraceae & spring \\
\hline CLAPUR & Clarkia purpurea ssp. quadrivulnera & Onagraceae & small-flowered godetia \\
\hline COLGRA & Collomia grandiflora & Polemoniaceae & large-flowered collomia \\
\hline COLHET & Collomia heterophylla & Polemoniaceae & varied-leafed collomia \\
\hline CROMUL & Crocidium multicaule & Asteraceae & spring gold \\
\hline DELLEU & Delphinium leucophaeum & Ranunculaceae & pale larkspur \\
\hline
\end{tabular}




\begin{tabular}{|c|c|c|c|}
\hline SPECIES CODE & TAXON & FAMILY NAME & COMMON NAME \\
\hline DELORE & Delphinium oreganum & Ranunculaceae & Willamette Valley larkspur \\
\hline DODHEN & Dodecatheon hendersonii & Primulaceae & Henderson's shooting star \\
\hline ERILAN & Eriophyllum lanatum & Asteraceae & eriophyllum \\
\hline ERYORE & Erythronium oregonum & Liliaceae & Oregon fawn-lily \\
\hline FRAVES & Fragaria vesca & Rosaceae & woodland strawberry \\
\hline FRIAFF & Fritillaria affinis & Liliaceae & chocolate lily \\
\hline GEUMAC & Geum macrophyllum & Rosaceae & largeleaf avens \\
\hline HETRAR & Heterocodon rariflorum & Campanulaceae & rareflower heterocodon \\
\hline HEUMIC & Heuchera micrantha & Saxifragaceae & Pacific alumroot \\
\hline LEPBIC & Leptosiphon bicolor & Polemoniaceae & true baby stars \\
\hline LILCOL & Lilium columbianum & Liliaceae & tiger lily \\
\hline LITPAR & Lithophragma parviflorum & Saxifragaceae & smallflower woodland star \\
\hline MICINT & Micranthes integrifolia & Saxifragaceae & wholeleaf saxifrage \\
\hline MICORE & Micranthes oregana & Saxifragaceae & Oregon saxifrage \\
\hline MICRUF & Micranthes rufidula & Saxifragaceae & redwool saxifrage \\
\hline MICGRA & Microsteris gracilis & Polemoniaceae & slender phlox \\
\hline MITCAU & Mitella caulescens & Saxifragaceae & star-shaped mitrewort \\
\hline MOEMAC & Moehringia macrophylla & Caryophyllaceae & big-leaf sandwort \\
\hline POTGLA & Potentilla glandulosa & Rosaceae & sticky cinquefoil \\
\hline POTGRA & Potentilla gracilis & Rosaceae & graceful cinquefoil \\
\hline PROHOO & Prosartes hookeri & Liliaceae & Hooker's fairy bells \\
\hline PRUVUL & Prunella vulgaris & Lamiaceae & heal-all, self-heal \\
\hline RANFLA & Ranunculus flammula & Ranunculaceae & lesser spearwort \\
\hline RANOCC & Ranunculus occidentalis & Ranunculaceae & western buttercup \\
\hline RANORT & Ranunculus orthorhynchus & Ranunculaceae & straightbeak buttercup \\
\hline RANUNC & Ranunculus uncinatus & Ranunculaceae & little buttercup \\
\hline SANANN & Sanguisorba annua & Rosaceae & annual burnet \\
\hline SEDSPA & Sedum spathulifolium & Crassulaceae & broadleaf stonecrop \\
\hline SIDCAM & Sidalcea campestris & Malvaceae & meadow checkermallow \\
\hline SPIBET & Spiraea betulifolia & Rosaceae & birchleaf spiraea \\
\hline STACOO & Stachys cooleyae & Lamiaceae & Cooley's hedgenettle \\
\hline STARIG & Stachys rigida & Lamiaceae & rigid betony \\
\hline TELGRA & Tellima grandiflora & Saxifragaceae & large fringecup \\
\hline TIATRI & Tiarella trifoliata & Saxifragaceae & foamflower \\
\hline TOLMEN & Tolmiea menziesii & Saxifragaceae & piggyback plant \\
\hline TRIBOR & Trientalis borealis & Primulaceae & star flower \\
\hline VIOADU & Viola adunca & Violaceae & hookedspur violet \\
\hline VIOGLA & Viola glabella & Violaceae & stream violet \\
\hline
\end{tabular}


Table 4. Environmental attributes of 40 existing phenopoints. Attributes include elevation (in meters and feet), aspect, slope and soil texture.

\begin{tabular}{|c|c|c|c|c|c|}
\hline PHENOPOINT & ELEVATION (m) & ELEVATION (ft) & ASPECT & SLOPE (degrees) & SOIL TEXTURE \\
\hline CAC019 & 86.086 & 282 & East & 4.67 & Cobbly-Loamy \\
\hline $\mathrm{CAC} 022$ & 77.01 & 253 & East & 9.26 & Cobbly-Loamy \\
\hline $\mathrm{CAC} 047$ & 82.8 & 272 & Southeast & 6.85 & Cobbly-Loamy \\
\hline CAC051 & 86.96 & 285 & Southeast & 3.56 & Cobbly-Loamy \\
\hline CAC056 & 73.29 & 240 & East & 10.27 & Cobbly-Loamy \\
\hline CAC065 & 77.92 & 256 & Northeast & 9.99 & Unknown \\
\hline CB004 & 62.18 & 204 & Southeast & 2.26 & Unknown \\
\hline CB009 & 61.07 & 200 & North & 2.29 & Unknown \\
\hline CB021 & 60.79 & 199 & Northwest & 8.23 & Unknown \\
\hline $\mathrm{CB} 022$ & 57.73 & 189 & North & 4.47 & Unknown \\
\hline CB043 & 68.03 & 223 & East & 1.38 & Unknown \\
\hline $\mathrm{CB} 060$ & 64.38 & 211 & Northwest & 8.85 & Unknown \\
\hline CMLL002 & 159.08 & 522 & Southeast & 5.84 & Silty-Loamy \\
\hline CMLL010 & 155.95 & 512 & South & 7.32 & Silty-Loamy \\
\hline CMLL012 & 156.69 & 514 & Southwest & 7.94 & Silty-Loamy \\
\hline CMLP010 & 203.52 & 668 & South & 6.12 & Silty-Loamy \\
\hline CMLP012 & 195.74 & 642 & South & 8.99 & Silty-Loamy \\
\hline CMLP014 & 193.83 & 636 & South & 9 & Silty-Loamy \\
\hline CMLP025 & 198.72 & 652 & South & 7.08 & Silty-Loamy \\
\hline CMQW008 & 175.89 & 577 & Southwest & 7.81 & Silty-Loamy \\
\hline CMQW013 & 162.34 & 533 & South & 8.46 & Silty-Loamy \\
\hline CMQW015 & 151.69 & 498 & South & 11.89 & Silty-Loamy \\
\hline CMQW022 & 165.72 & 544 & South & 10.43 & Silty-Loamy \\
\hline CMQW023 & 160.91 & 528 & South & 6.16 & Silty-Loamy \\
\hline CMQW024 & 194.91 & 639 & Southwest & 6.46 & Silty-Loamy \\
\hline PCF025 & 51.92 & 170 & East & 5 & Unknown \\
\hline PCF027 & 63.33 & 208 & Southwest & 7.37 & Unknown \\
\hline PCF029 & 48.5 & 159 & Northwest & 7.86 & Loamy \\
\hline PCF030 & 54.21 & 178 & North & 8.17 & Unknown \\
\hline PCF033 & 44.97 & 148 & West & 4.02 & Loamy \\
\hline PCF035 & 58.45 & 192 & West & 4.11 & Unknown \\
\hline PCF042 & 46.32 & 152 & West & 7.22 & Loamy \\
\hline WNF007 & 44.84 & 147 & Northeast & 20.9 & Unknown \\
\hline WNNB009 & 24.67 & 81 & Northeast & 12.28 & Unknown \\
\hline WNNB010 & 25.82 & 85 & Northeast & 4.21 & Unknown \\
\hline WNSB001 & 19.21 & 63 & East & 4.29 & Water \\
\hline WNSB002 & 18.89 & 62 & Northeast & 6.36 & Water \\
\hline WNSB004 & 26.9 & 88 & Northeast & 17.61 & Unknown \\
\hline WNSB011 & 20.47 & 67 & East & 12.02 & Unknown \\
\hline WNSB013 & 39.4 & 129 & Southeast & 8.67 & Unknown \\
\hline
\end{tabular}


Appendix B: GIS Maps
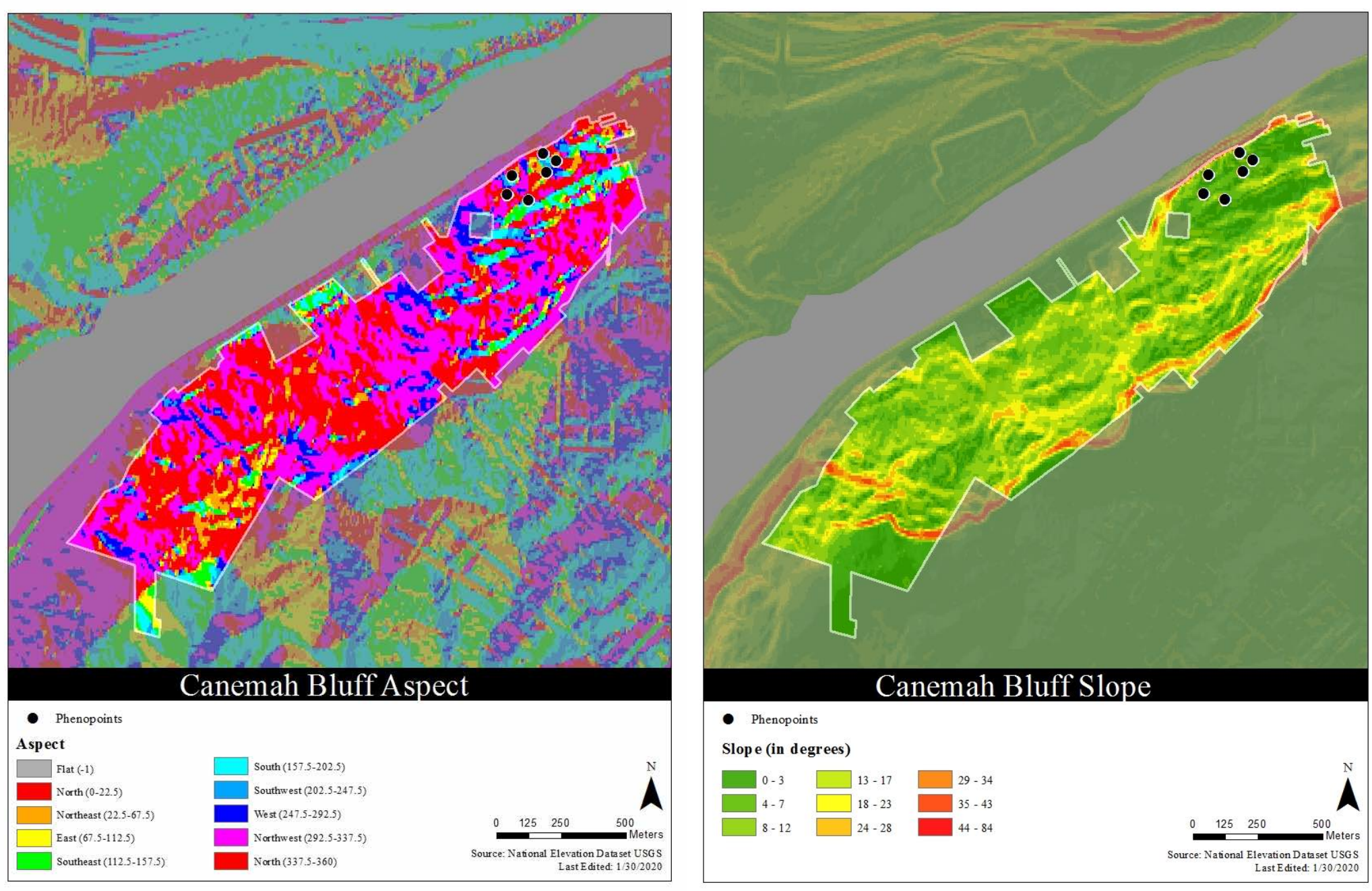

Figures 13 and 14. Environmental attribute maps of Canemah Bluff, showing aspect and slope. 

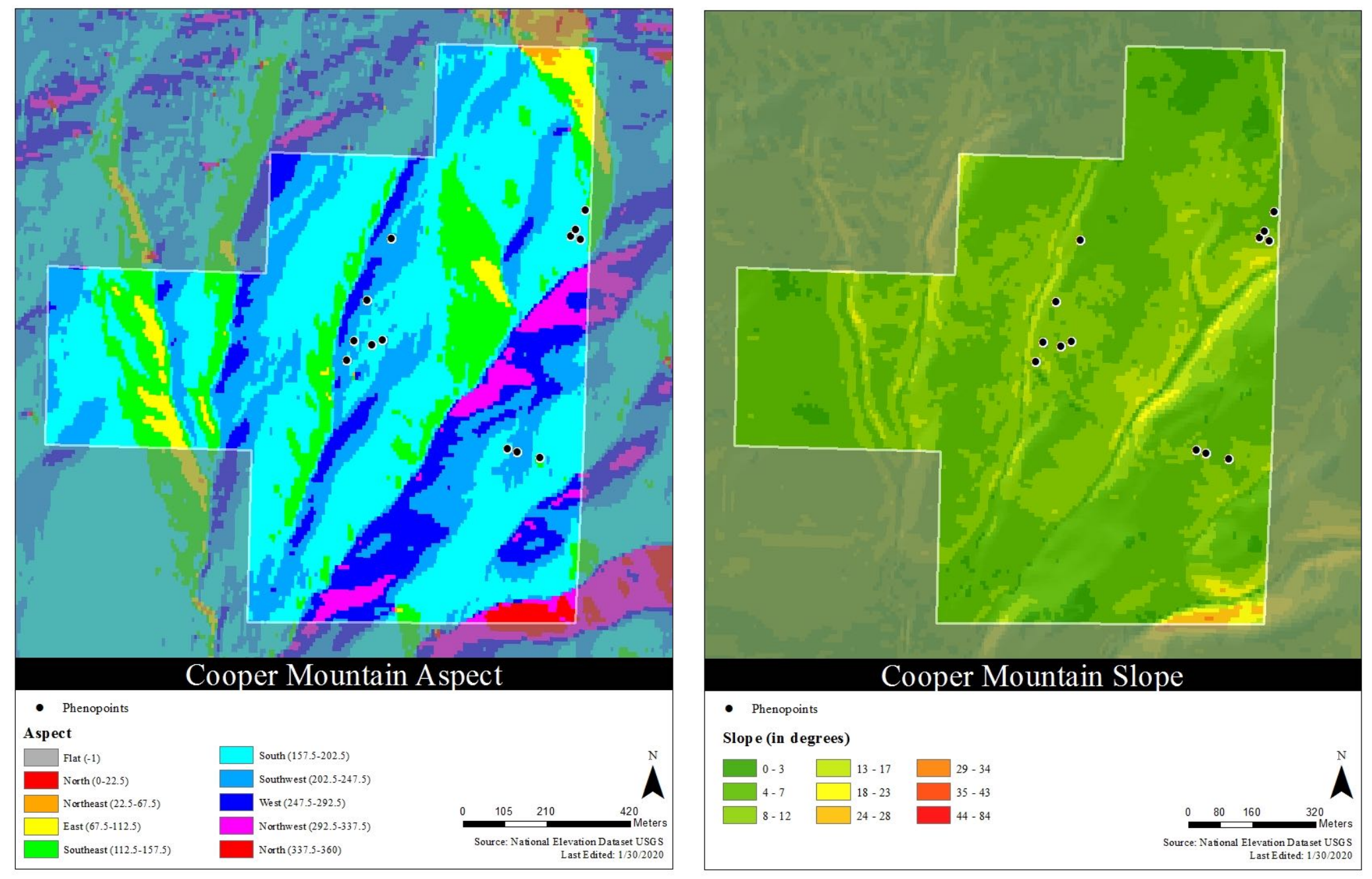

Figures 15 and 16. Environmental attribute maps of Cooper Mountain Nature Park, showing aspect and slope. 


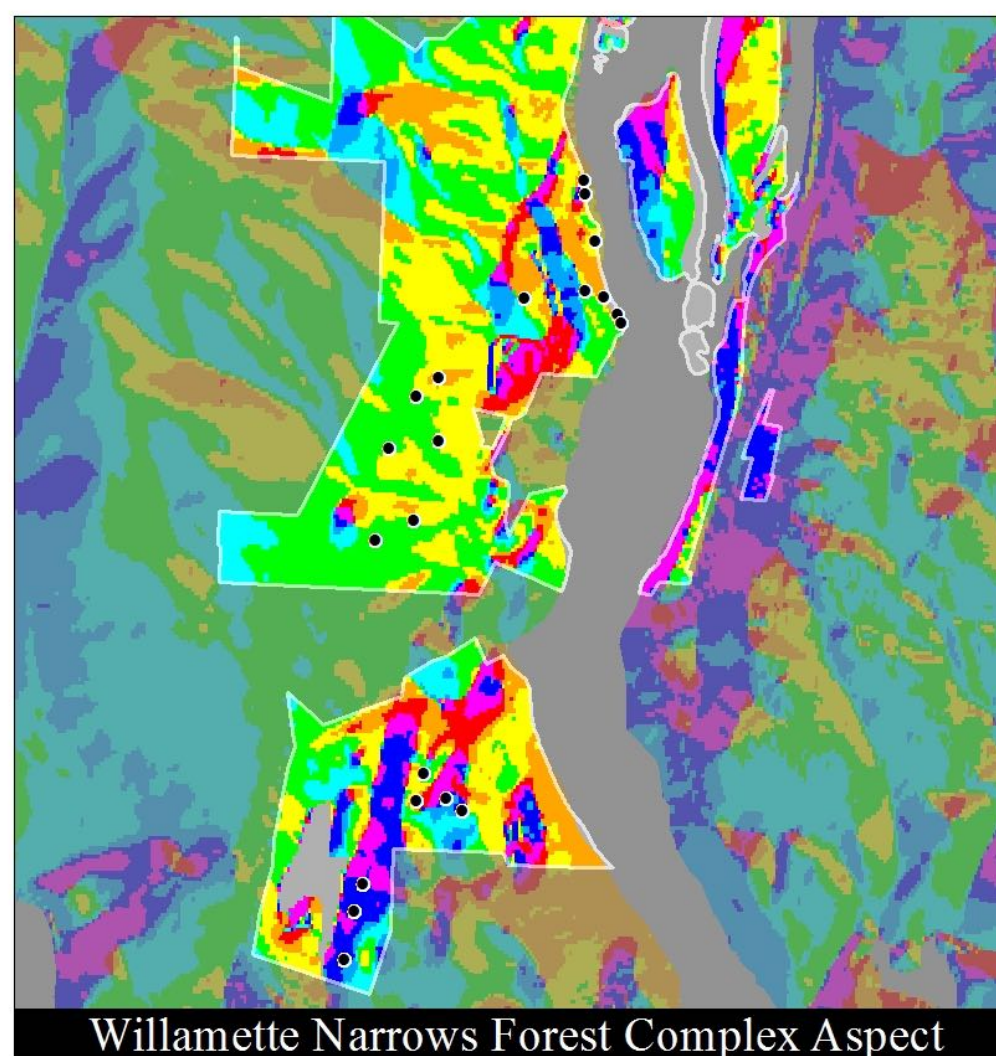

- Phenopoints

Aspect

\begin{tabular}{l} 
Aspect \\
\hline Flat (-1)
\end{tabular}

Flat (-1)
North (0-22.5)

Northeast (22.5-67.5)

East (67.5-112.5)

Southeast (112.5-157.5)
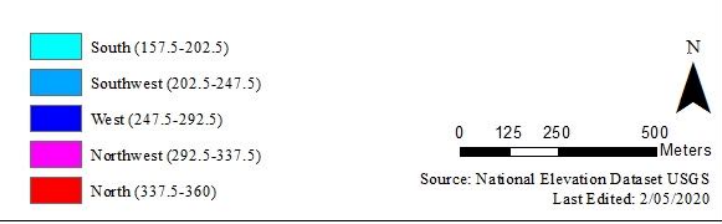

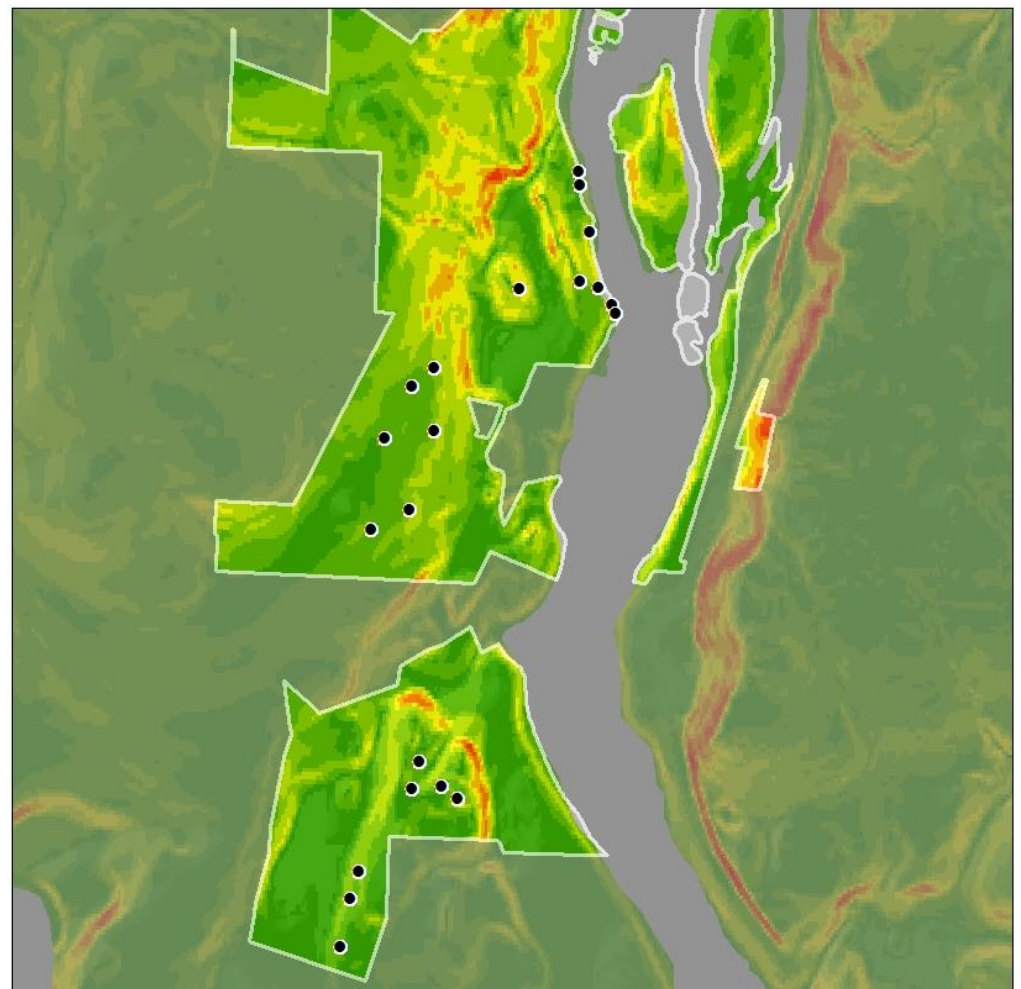

Willamette Narrows Forest Complex Slope

- Phenopoints

Slope (in degrees)

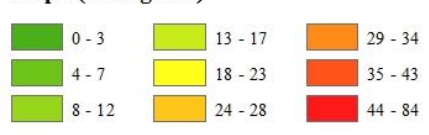

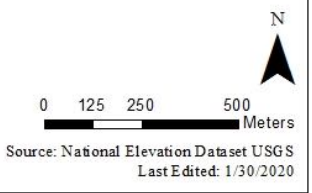

Figures 17 and 18. Environmental attribute map of Willamette Narrows Forest Complex, showing aspect and slope. 


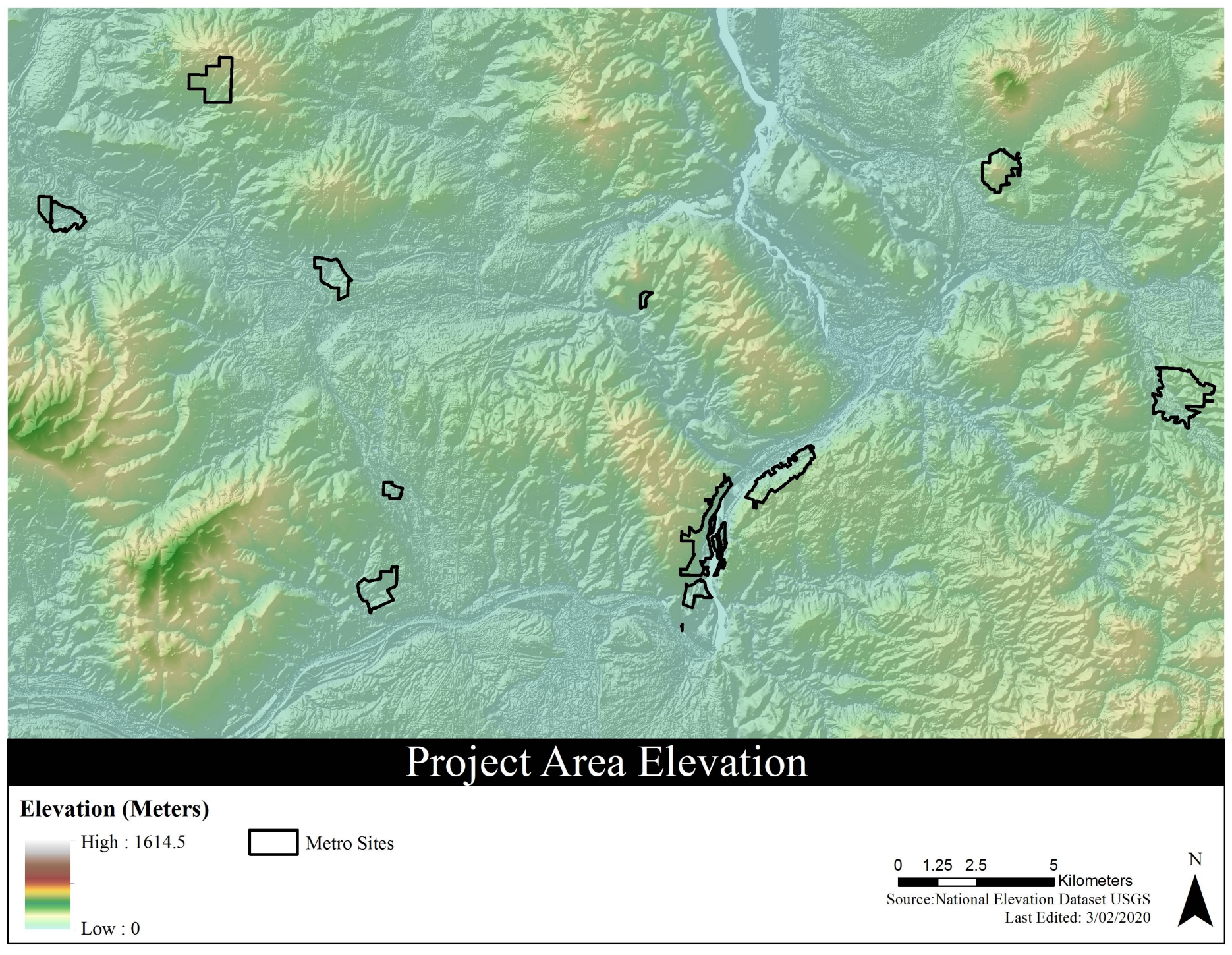

Figure 19. Environmental attribute map of project area, showing elevation. 


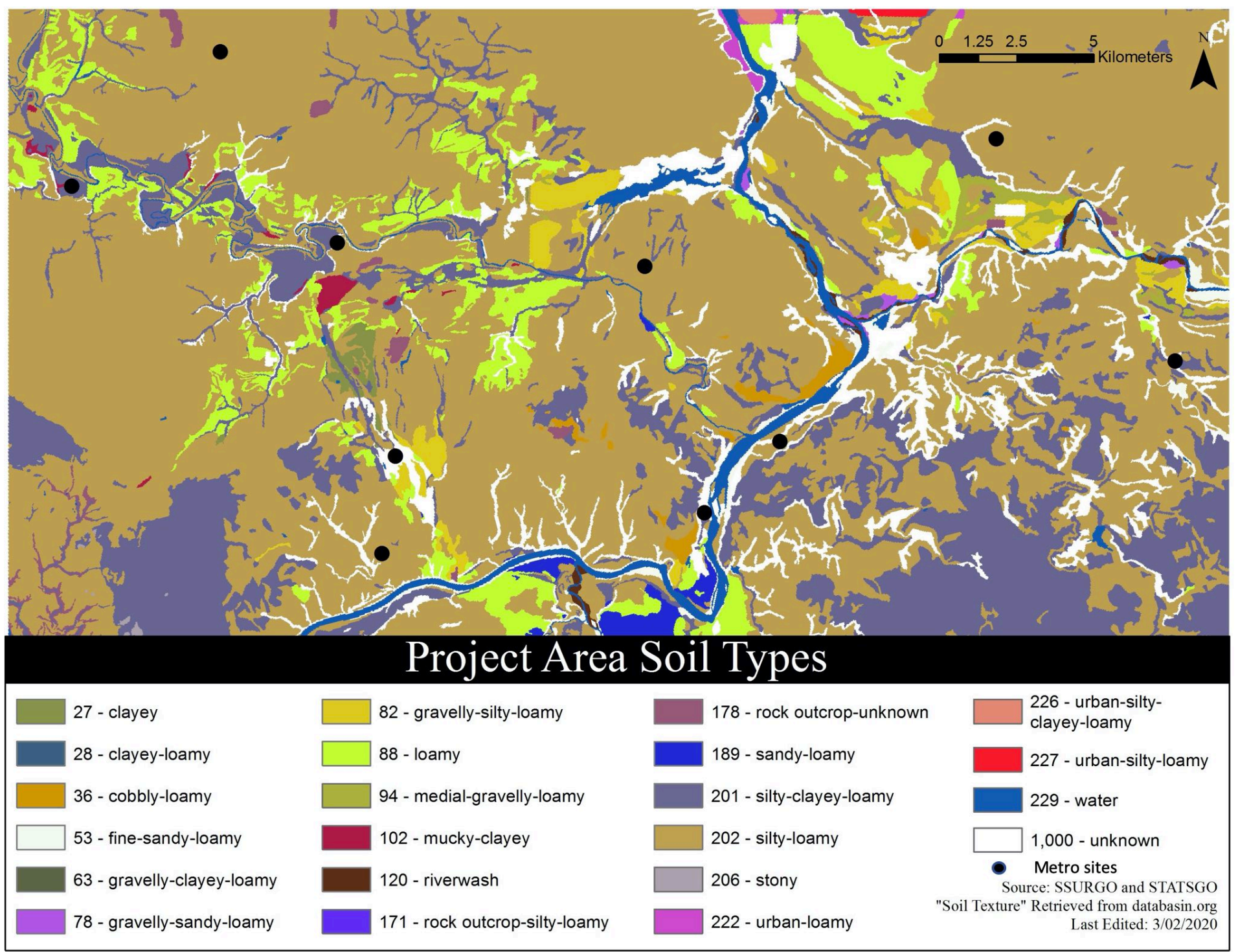

Figure 20. Environmental attribute map of project area, showing soil types. 


\section{Permanent Field Marker Recommendations}

1) Low-profile survey stakes made of galvanized steel will not rust and can be located with a metal detector if necessary. https://www.amazon.com/Survey-Marker-Profile-Stakes-Hi-Vis/dp/B00JHNZOT8.

2) Bronze survey markers are set in concrete to increase durability. https://www.berntsen.com/Surveying/Concrete-Survey-Markers/Bronze-Concrete-SurveyMarkers/ctl/ViewProduct/mid/584/ItemID/374?gclid=EAIaIQobChMIodDDuNDI5wIV7yCtBh2 C3ASQEAQYAiABEgIXcPD_BwE 
